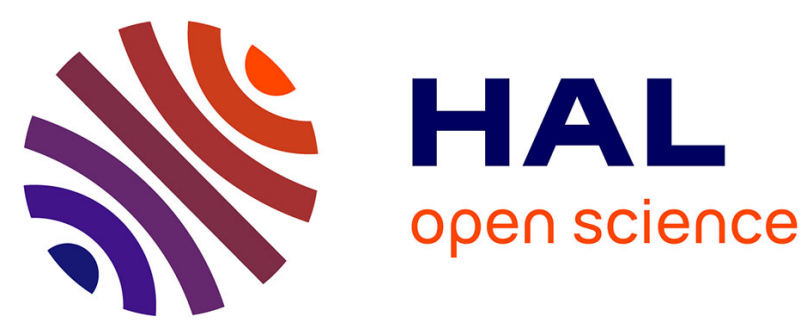

\title{
Green earth pigments dispersions: Water dynamics at the interfaces
}

Agathe Fanost, Maguy Jaber, Laurence de Viguerie, Jean-Pierre Korb, Pierre E Levitz, Laurent J Michot, Guillaume Mériguet, Anne-Laure Rollet

\section{- To cite this version:}

Agathe Fanost, Maguy Jaber, Laurence de Viguerie, Jean-Pierre Korb, Pierre E Levitz, et al.. Green earth pigments dispersions: Water dynamics at the interfaces. Journal of Colloid and Interface Science, 2021, 581 (Pt B), pp.644-655. 10.1016/j.jcis.2020.07.085 . hal-03079935

\section{HAL Id: hal-03079935 https://hal.sorbonne-universite.fr/hal-03079935}

Submitted on 17 Dec 2020

HAL is a multi-disciplinary open access archive for the deposit and dissemination of scientific research documents, whether they are published or not. The documents may come from teaching and research institutions in France or abroad, or from public or private research centers.
L'archive ouverte pluridisciplinaire HAL, est destinée au dépôt et à la diffusion de documents scientifiques de niveau recherche, publiés ou non, émanant des établissements d'enseignement et de recherche français ou étrangers, des laboratoires publics ou privés. 


\section{Green Earth pigments dispersions: water dynamics at the interfaces}

Agathe Fanost ${ }^{1,2}$, Maguy Jaber ${ }^{2}$, Laurence de Viguerie ${ }^{2}$, Jean-Pierre Korb ${ }^{1}$, Pierre E. Levitz ${ }^{1}$, Laurent J. Michot ${ }^{1}$, Guillaume Mériguet ${ }^{1}$, Anne-Laure Rollet ${ }^{1, *}$

1. Sorbonne Université, CNRS, laboratoire PHysico-chimie des Electrolytes et Nanosystèmes InterfaciauX, PHENIX, F-75005 Paris, France

2. Sorbonne Université, CNRS, laboratoire d'Archéologie Moléculaire et Structurale, LAMS, F-75005 Paris, France

Keywords : celadonite, glauconite, phyllosilicate, Fast Field Cycling NMR relaxometry, water surface interaction, diffusion

\section{Abstract}

Hypothesis: The objective is to elucidate the multiscale dynamics of water within natural mixtures of minerals, green earth pigments that are mainly composed of phyllosilicates containing large amount of iron. In particular, the interaction of water with the different kinds of surfaces has to be probed. One issue is to examine the influence of surface type, basal or edge, on the dispersion quality.

Experiment: The study was carried out using ${ }^{1} \mathrm{H}$ variable field NMR relaxometry on various green earth pigment dispersions and concentrations. To analyse the data, a new analytical model was developed for natural phyllosilicates containing large amount of paramagnetic centres.

Finding: The proposed theoretical framework is able to fit the experimental data for various samples using few parameters. It allows to determining water diffusion and residence times in complex phyllosilicate dispersions. Furthermore, it makes it possible to differentiate the contribution of the basal and edge surfaces and their respective surface area in interaction with water. Moreover, NMR relaxation profile reveals to be highly sensitive to the structural aspect of the phyllosilicates and to the accessibility of water to iron, hence allowing to discriminate clearly between two very similar phyllosilicates (glauconite and celadonite) that are difficult to distinguish by standard structural methods.

\section{Introduction}

Clay dispersions are encountered in countless domains [1],[2]. Just within the field of cultural heritage, they occur in pottery, sculpture, fresco and tempera paint. Tempera is a generic term which is used to describe paint made of pigments bound in an aqueous proteinaceous medium such as animal glue or egg. It is often used nowadays more specifically to describe the egg-tempera medium. This technique described since Antiquity and still used today was at its culmination during the Middle Age. Detailed information about the paint practices at that time can be found in the book written by Cennino Cennini (Treatise of painting) [3],[4]. Together with malachite $\left(\mathrm{Cu}_{2} \mathrm{CO}_{3}(\mathrm{OH})_{2}\right)$ and verdigris (acetic acid + copper), green earth (GE) pigments are among the oldest green pigments ever used [5],[6]. They have been widely used in tempera paintings especially for the underlayer of flesh or as the bole, under gold leaf, and more occasionally for draperies [3]. They were and are still extracted from various ore deposits and are naturally composed of a mixture of minerals whose exact composition varies according to the location of deposit. 
Still, the most abundant minerals in green earths are either celadonite or glauconite [7],[8]. These two species are both phyllosilicates from the mica group and both contain structural $\mathrm{Fe}^{\mathrm{II}}$, which explains their green colour, the hues of which depend on the exact $\mathrm{Fe}^{\mathrm{II}} / \mathrm{Fe}^{\mathrm{III}}$ ratio. These two minerals are structurally very close, which renders their accurate identification rather difficult [9],[10],[11]. Their mechanism of formation (for celadonite, cooling of volcanic rocks in vesicular cavities and fractures and for glauconite, marine sedimentation [12],[13]) leads to differences in their distribution over the world and in their concentration within the deposits [14].

Understanding the relationship between painter's choices, green earth composition and tempera composition requires a deeper knowledge of the structure and dynamics of the complex aqueous suspensions used by the artists. Owing to the complexity of such systems (mixtures of several minerals of various particle sizes with natural organic binder), we first focus here on an elementary sub-system, i.e. aqueous suspensions of various green earth materials in the absence of any organic binder and try to better assess the links between green earth nature and the interaction of water with pigment surfaces. For reaching such an aim, we use NMR relaxometry that has proven to be an efficient tool to evaluate particle dispersions [15],[16], [17], their stability [18], [19], [20], [21], [22] and especially the interaction of the solvent with the colloidal surfaces [19], [23], [24], [25]. The sensitivity of NMR relaxation rates of the solvent to the interaction with interfaces makes it even possible to evidence the counterion specific effect with charged surfaces [26], [27]. However, most of these studies are limited to a fixed magnetic field investigation, thus offering only a narrow window on the phenomena at play. In the present study, we employ variable NMR relaxometry using the Fast Field Cycling (FFC) method [28]. Spanning the ${ }^{1} \mathrm{H}$ frequency from $10 \mathrm{kHz}$ to $40 \mathrm{MHz}$ allows to investigate dynamics over a time range from approximately one nanosecond up to one microsecond, i.e. a window that is ideal to probe the solvent dynamics in the vicinity of interfaces [29],[30].

The present work is organized as follows. First using various green earth minerals, we investigate the effect of solid concentration on water dynamics. We then investigate the influence of green earth composition on the NMR relaxometry features and the various relaxation profiles are further analysed using a theoretical model of the solvent dynamics. Finally, we assess the impact of adding montmorillonite, a swelling phyllosilicate, on the relaxation profiles. It must be pointed out that even if the present study was motivated by cultural heritage issues, the data and methodology developed could bear some relevance to numerous fields where clay/water mixtures play a role such as geoscience [31],[32],[33], water treatment [34],[35],[36] or cosmetics and pelotherapy [1],[37],[38],[2]. Just to cite few examples of different horizons, landslides can result from the existence of a water saturated clay layer in the ground, dilute clay dispersions can be used in various processes, concentrated clay dispersions are the basis of most of pelotherapy.

\section{Experimental}

\section{Samples}

\section{Green Earth and Mineral compositions}

The used pigments are listed in Table 1 together with their minerals composition (according to Fanost et al. [11]). An additional mineral (glauconite) was provided by the geological and mineral gallery of the "Museum National d'Histoire Naturelle" (MNHN, Paris). The average chemical composition of each mineral is given in supplementary material (Table S1). In the case of France GE, the X-ray diffraction (XRD) pattern was measured in order to identify the main mineral component (Figure S1). 
Table 1: list of pigments with the main mineral component and the secondary minerals components according Fanost et al. The proportions are given in $\% w t$.

\begin{tabular}{|c|c|c|c|c|}
\hline Pigment & Main mineral & other main minerals & Supplier & Reference \\
\hline Cyprus GE & Celadonite $(70 \%)$ & $\begin{array}{l}\text { Montmorillonite (16\%), } \\
\text { Quartz }(8 \%)\end{array}$ & Kremer Pigmente & K17400 \\
\hline $\begin{array}{l}\text { Cyprus GBE } \\
\text { (Green Blue Earth) }\end{array}$ & $\begin{array}{l}\text { Celadonite/Ferrocelado } \\
\text { nite }(66 \%) \text {, }\end{array}$ & $\begin{array}{l}\text { Montmorillonite (18\%), } \\
\text { Anhydrite }(5 \%) \\
\text { Anorthite }(11 \%)\end{array}$ & Kremer Pigmente & K17410 \\
\hline Russia GE & Glauconite & Quartz, Calcite & Kremer Pigmente & K11110 \\
\hline Bohemian GE & Glauconite (88\%) & $\begin{array}{l}\text { Montmorillonite (10\%), } \\
\text { Quartz }(2 \%)\end{array}$ & Kremer Pigmente & K40810 \\
\hline Sennelier GE & Gypsum & $\begin{array}{l}\text { Montmorillonite, } \\
\text { Calcite, } \\
\text { Quartz }\end{array}$ & Sennelier & 213 \\
\hline Brentonico GE & Gypsum (45\%) & $\begin{array}{l}\text { Montmorillonite (33\%), } \\
\text { Calcite }(21 \%)\end{array}$ & Laverdure & 346378 \\
\hline Nicosie GE & Gypsum & $\begin{array}{l}\text { Quartz, } \\
\text { Calcite }\end{array}$ & Laverdure & 346379 \\
\hline Veronese GE & Calcite & Anorthite & Kremer Pigmente & K11000 \\
\hline France GE & Gypsum & & Kremer Pigmente & K40830 \\
\hline
\end{tabular}

It is important to underline that natural minerals contain impurities, some of them containing iron atoms that have noticeable effects in NMR studies.

Samples preparation for NMR measurements

Several mixtures with earth/water ratio ranging between 20 to 60 weight $\%$ were prepared by mimicking traditional paint process, i.e. using a glass muller to ensure the homogeneity of the dispersions even in concentrated pasty samples [4]. Powdered green earth was laid on a glass plate, water was spread over it and both components were mixed using the muller until the mixture was homogenous in texture and colour. The mixing time was usually around 2 to 3 minutes. The samples were put in glass tubes of $10 \mathrm{~mm}$ in diameter and only $40 \mathrm{~mm}$ in length closed by a silicon cap. In order to prevent evaporation during the experiment, the tube has been shortened as compared with standard NMR $10 \mathrm{~mm}$ tube and an extension was added to place the tube at magnetic centre of the relaxometers (figure S6). The volume fraction $\Phi_{v}$ is calculated using the density of each mineral deduced from crystallographic structure. 


\section{Montmorillonite synthesis}

Pure Na-montmorillonite was synthesised to avoid the presence of any impurities. Its chemical formula per half unit cell is can be written as $\mathrm{Na}_{x}{ }^{\mathrm{IV}}\left(\mathrm{Si}_{4}\right)^{\mathrm{VI}}\left(\mathrm{Al}_{2-x} \mathrm{Mg}_{x} \curvearrowleft\right) \mathrm{O}_{10}(\mathrm{OH}, \mathrm{F})_{2}$ with $x$, the substitution rate and $\square$ an octahedral vacancy.

The hydrothermal synthesis was performed in fluorinated medium at $220^{\circ} \mathrm{C}$. Aerosil 130 (Evonik); Boehmite (Pural-Sasol, 74\% wt), magnesium acetate tetrahydrated (Sigma-Aldrich, 99\% wt), sodium acetate (Sigma-Aldrich, 99\% wt), hydrofluorhydric acid (sigma Aldrich, 48\% wt) and distilled water were mixed to form the gel precursor of montmorillonite with a $\mathrm{pH}$ of 5.5. The later was left $3 \mathrm{~h}$ under stirring before being placed in a Teflon liner inserted in a steel autoclave. After 5 days at $220^{\circ} \mathrm{C}$, the $\mathrm{pH}$ decreased to 4 and the solid was recovered after centrifugation, washed with distilled water and dried at $50{ }^{\circ} \mathrm{C}$ overnight.

\section{Characterization}

\section{NMR relaxometry}

The water ${ }^{1} \mathrm{H}$ longitudinal relaxation rates $R_{1}=\frac{1}{T_{1}}$ were measured on two different NMR relaxometers. Preliminary measurements were performed at $20 \mathrm{MHz}$, using a Bruker Minispec mq20 via an inversion-recovery sequence with 32 recovery delays ranging from $40 \mu$ s to $10 T_{1}$ approximately. The $90^{\circ}$ pulse duration was optimized at $9.7 \mu$ s. The low frequency domain from $10 \mathrm{kHz}$ to $30 \mathrm{MHz}\left({ }^{1} \mathrm{H}\right.$ frequency) was further explored using a Stelar SpinMaster relaxometer. In this case, $T_{1}$ was measured using a pre-polarized sequence from $10 \mathrm{kHz}$ to $10 \mathrm{MHz}$ and a nonpolarized sequence from $10 \mathrm{MHz}$ to $30 \mathrm{MHz}$ [39]. The recycle delay was set to $0.5 \mathrm{~s}$, the polarization was done at $20 \mathrm{MHz}$, the acquisition at $16.35 \mathrm{MHz}$, the $90^{\circ}$ pulse duration was optimized at $9.5 \mu \mathrm{s}$. For the $T_{1}$ determination, 32 logarithmically spaced recovery delays between approximately $0.01 T_{1}$ and $4 T_{1}$ were used. Hence, the sample almost completely filled the tube and no evaporation occurs. The samples were thermostated at $298 \mathrm{~K}$ (except otherwise stated) using regulated air flux by the built-in VTC91.

\section{Scanning Electron Microscopy}

Analyses were carried out on a Zeiss Sigma 300 SEM equipped with a Bruker Quantax 6030 EDS spectrometer at $20 \mathrm{kV}$ for an acquisition of 500 kcounts. Before the analysis, each powder sample was dispersed on a stub with double-sided carbon tape and was subsequently coated with a carbon layer by evaporation. The sample were photographed by Scanning Electron Microscopy with a FEI NNS450 SEM instrument, the parameters were HV $20 \mathrm{kV}$, diaph. $30 \mu \mathrm{m}$, spot 4.5, WD 6,5 mm and G was variable.

\section{Transmission Electron Microscopy}

TEM study of the samples was performed on a JEOL 2010 microscope, $200 \mathrm{kV}$ LaB6 coupled Orius camera, from Gatan Company. Samples in the form of bulk powders were suspended in ethanol and then deposited on 400 mesh copper grids covered with an ultrathin carbon membrane of 2-3 $\mathrm{nm}$ in thickness.

\section{Results and discussion}

The solid fraction range studied in the present work is relevant to the paint application and the sample aspect goes from liquid to paste. In these mixtures, the magnetization evolutions versus time that are used to determine the ${ }^{1} \mathrm{H}$ relaxation rates are monoexponential function at all the frequencies $(10 \mathrm{kHz}-30 \mathrm{MHz})$. Bi-exponential variation ( $T_{2}$ measurements) is observed with concentrated smectite suspensions in electrolyte solutions [40] while here the dispersions are prepared with deionized water. 


\section{Effect of dilution}

The viscosity and thus the ability for the paint to cover surfaces efficiently are highly dependent on the solid content of the mixture. The NMR relaxation profiles were therefore measured for several green earth volume fractions. In the standard tempera recipe, the mass fraction of green earth is $\approx 30 \mathrm{wt} \%$, i.e. a volume fraction of about $13 \%$. It must be pointed out that due to the presence of a binder, for a given volume fraction, the tempera recipe is more stable than mixtures composed solely of green earth and water that are more prone to sedimentation. In consequence, the range of volume fraction investigated in the present study extends from the common tempera value (i.e. $13 \%$ ) up to $30 \%$. Above $30 \%$, the mixture is generally a paste that is barely spreadable and then rather irrelevant to painting situations. With regard to the list provided in Table 1, the influence of volume fraction has been investigated for: GE Bohemian, GE Cyprus, GBE Cyprus, GE Russia, GE Sennelier, GE France and montmorillonite.
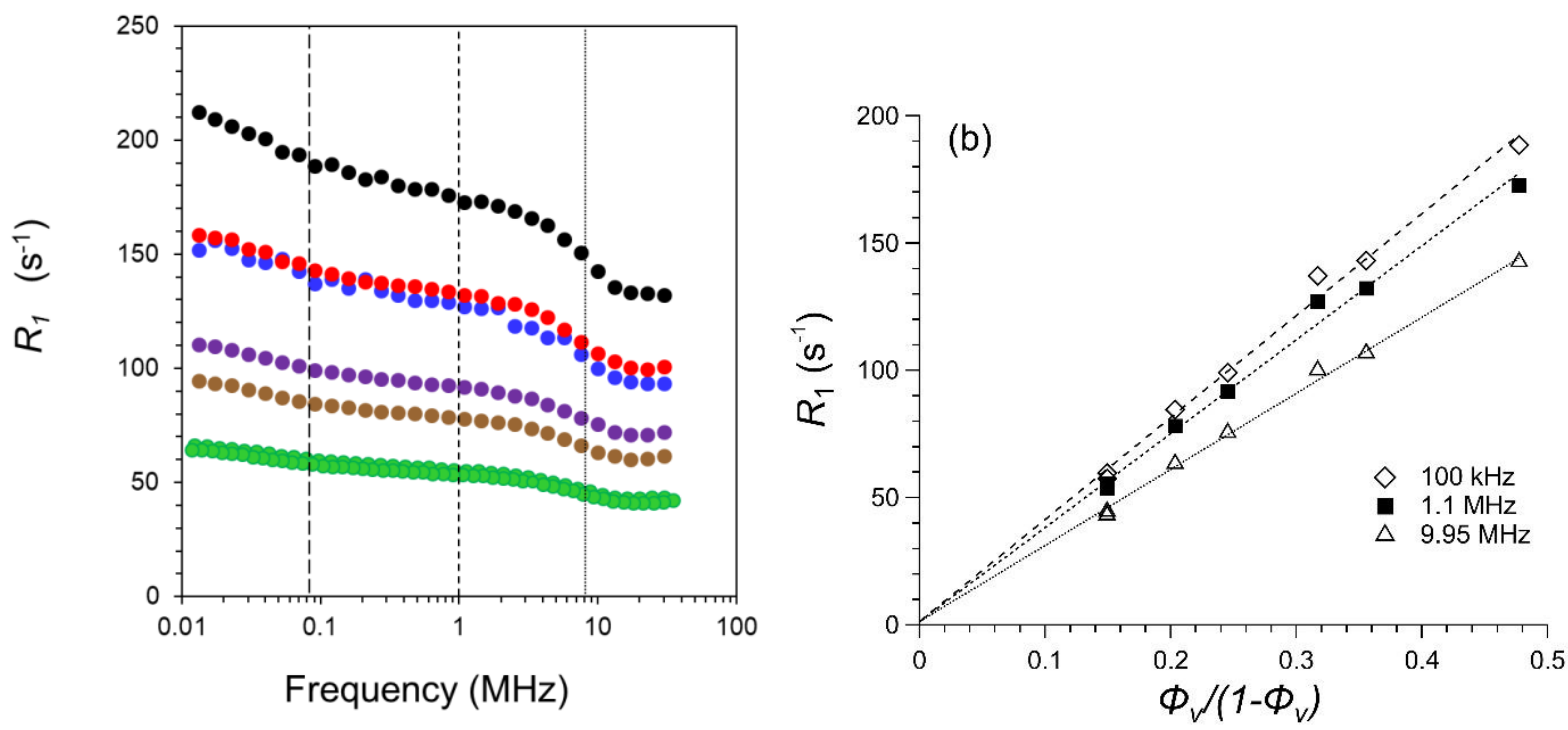

Figure 1: (a) ${ }^{1} H$ relaxation rate profile of water in GE Bohemian for several $\Phi_{V}: 0.13$ (green), 0.18 (brown), 0.21 (purple), 0.26 (blue), 0.27 (red) and 0.33 (black). (b) Variation of $R_{1}$ as a function of $\Phi_{V}$ at $100 \mathrm{kHz}, 1.1 \mathrm{MHz}$ and $9.95 \mathrm{MHz}$ with the corresponding linear regression.

The evolution of relaxation profiles for $\Phi_{V}$ is very similar for GE Bohemian, GE Cyprus, GE Russia, GBE Cyprus, GE France and GE Sennelier. Consequently, only GE Bohemian is presented (Figure 1) in the main text whereas the cases of other green earths (GE Cyprus, GE Russia, GBE Cyprus, GE Sennelier, GE France) are reported in the supplementary materials (Figure S2 and S3). Figure 1a clearly reveals that the NMR relaxation profile is shifted downwards with decreasing $\Phi_{V}$. Plotting the relaxation rate $R_{1}$ at given frequency as a function of $\Phi_{V} /\left(1-\Phi_{V}\right)($ Figure 1b) further reveals that the dependence is linear on the whole frequency range investigated. In consequence, it is possible to rescale all the profiles for a given green earth by dividing $R_{1}$ by $\Phi_{V} /\left(1-\Phi_{V}\right)$ allowing us to obtain a master curve, called relaxivity profile. The existence of this master curve reveals that (i) aqueous suspension is homogeneous in the whole scale range investigated by NMR relaxometry whatever $\Phi_{V}$ (ii) the nature of the surface probed by the ${ }^{1} \mathrm{H}$ spins carried by water molecules does not change with dilution. In other words, we are in the fast exchange case between water molecules probing the surface and water molecules probing a "bulk" environment [41]. A detailed framework of this notion within fast field cycling relaxometry technique has been 
recently given by Fries and Belorizky [42]. $R_{l}$ Linear dependence with clay concentration has also been observed at fixed field in hectorite aqueous dispersion [43].

In contrast with all GE materials, sodium montmorillonite exhibits significantly different features. Indeed, as shown in Figure 2, for aqueous montmorillonite dispersions, the relaxivity, expressed as $r_{1}=R_{1} /\left(\Phi_{V} /\left(1-\Phi_{V}\right)\right)$, decreases with frequency but does not superimpose for different $\Phi_{V}$. This change in behaviour does not arise from a loss of the rapid exchange condition but can rather be assigned to the swelling of this mineral. Indeed, sodium montmorillonite has long been known to exhibit osmotic swelling [44], [45], [46], i.e. a swelling regime under which the average distance between layers increases linearly with decreasing volume fraction, which can at high dilution leads to full delamination. From the water ${ }^{1} \mathrm{H}$ spin perspective, the accessible surface changes upon dilution and $\operatorname{ergo}{ }^{1} \mathrm{H}$ relaxivity evolves with volume fraction.

As revealed in Table 1 green earth samples often contain significant amounts of montmorillonite. It may then appear surprising that the effect observed for pure montmorillonite does not affect the relaxivity curves of these materials. However, as explained above, the observed behaviour is linked to osmotic swelling. Such swelling only occurs for montmorillonite exchanged with monovalent cations. When divalent ions are compensating the clay, structural charge correlation forces due to the presence of multivalent ions prevent osmotic swelling and in water, whatever the dilution, swelling remains limited to crystalline swelling. The basal spacing therefore remains fixed at around $2 \mathrm{~nm}$, a distance that corresponds to the presence of around three water layers in the interlayer. In green earth environments, the compensating cation of montmorillonite are calcium, magnesium and potassium to a lesser extent. In such conditions, the osmotic swelling is prevented and the amount of accessible surface remains constant, which explains why the presence of montmorillonite does not prevent the existence of a master curve [47].

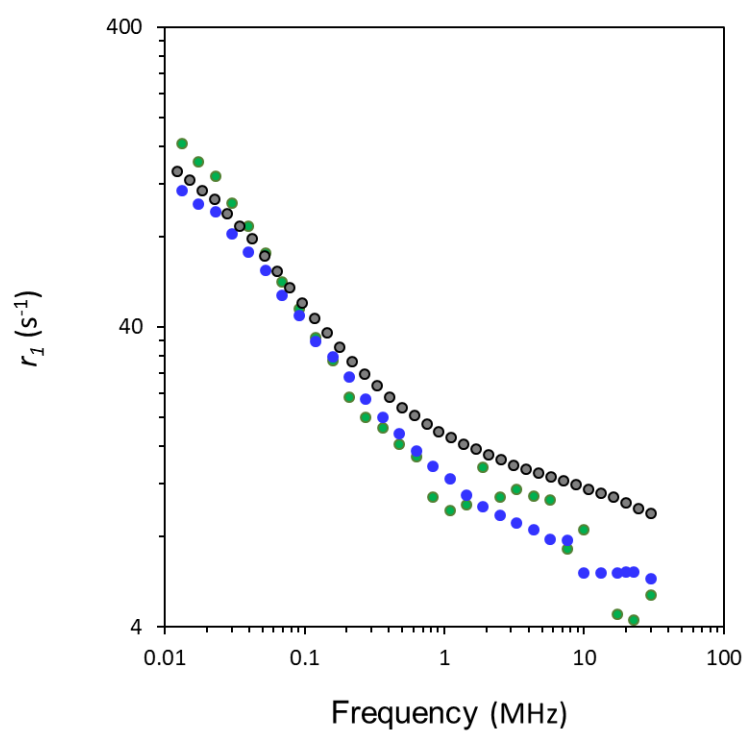

Figure $2:{ }^{1} H$ relaxivity $r_{1}=R_{I} /\left(\Phi_{V} /\left(1-\Phi_{V}\right)\right)$ profile of water in montmorillonite for $\Phi_{V}=0.36$ (green), 0.26 (blue) and 0.15 (black). 


\section{Green Earth minerals signature in the NMR relaxivity profile}

The NMR relaxivity profiles for various green earth suspensions in water are plotted in figure 3. Each pigment exhibits quite a different profile, however resemblance can be observed between some of them. In the first group, let it label group (a), one can include GE Bohemian, GE Russia and Glauconite Villers-sur-Mer. In the second group, group (b), one can include GE Brentonico, Green Blue Earth (GBE) Cyprus, GE Sennelier, GE Nicosie and GE France. Finally, GE Veronese, GE Cyprus and Celadonite Monte Baldo have a separate signature. Recently, a careful identification of the minerals present in these pigments has been carried out [11] and the result is recalled here in Table 1. A correlation appears between the NMR relaxometry profile and the main mineral present in the pigment. In group (a), where the profiles are the most similar in shape, the pigments are mainly constituted of glauconite. In group (b), the main component is gypsum for GE Brentonico, GE Sennelier, GE Nicosie and GE France but not for GBE Cyprus (celadonite-ferroceladonite). The main component for GE Veronese, GE Cyprus is calcite and celadonite, respectively. It then appears that there is no univocal link between relaxivity profiles and mineralogical composition, but that some clear tendencies show that NMR relaxometry could represent an interesting complementary tool for identifying the various GEs.

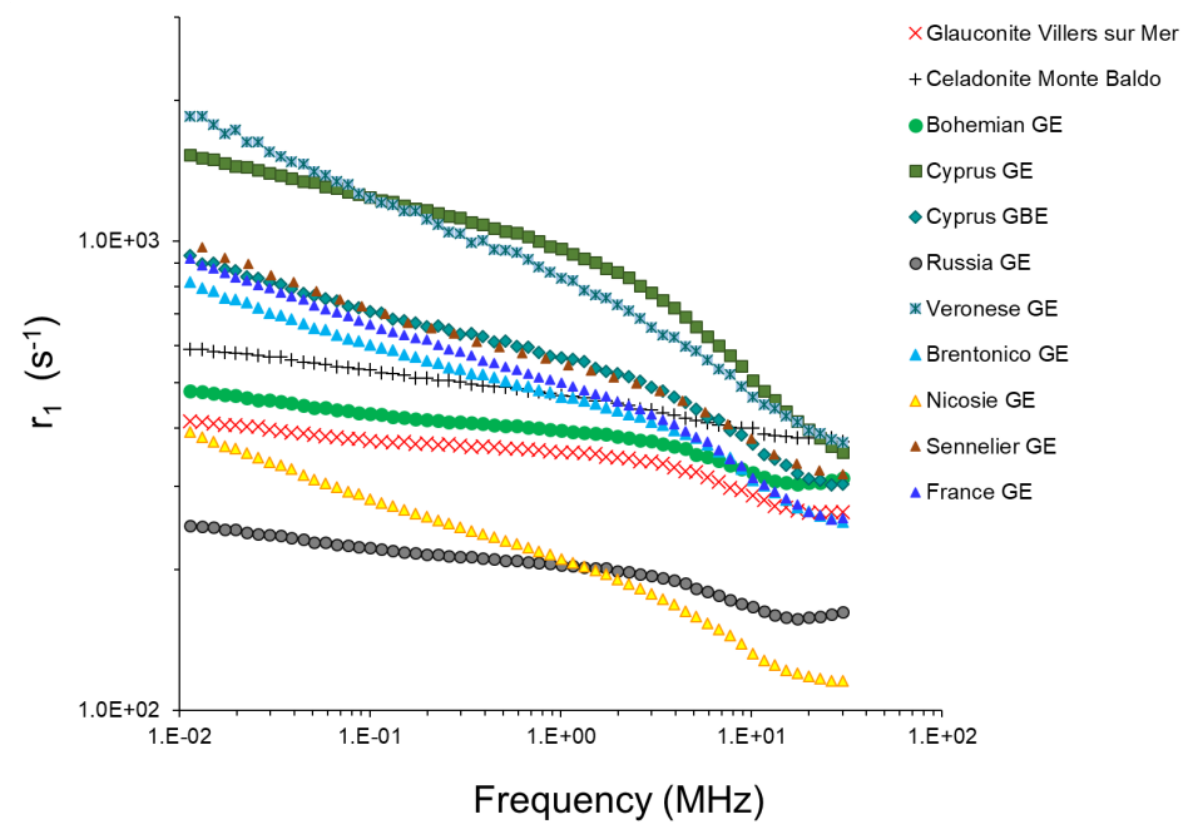

Figure $3:{ }^{1} \mathrm{H}$ relaxivity $r_{1}=R_{1} /\left(\Phi_{V} /\left(1-\Phi_{V}\right)\right)$ profile of water for several green earths.

It could be expected that pigments having the same principal mineral would have their NMR relaxation profile superimposed. Here only the shape is similar. This likely arises from differences in size distribution that would affect intensity while maintaining a constant shape. Indeed, the present study has been performed mainly on commercial pigments and the size of the particles is not controlled and has a broad distribution. The linear dependence of $R_{1}$ with the volume fraction reflects its dependence with the accessible surface area. In consequence, these curves can be used to compare the surface area per gram of green earth for a given family of mineral. Hence for the glauconite group (Villers-sur-Mer, Bohemian GE and Russia GE) and by using the Glauconite from Villerssur-Mer as a reference, the superposition of the NMR profiles is obtained by multiplying them by a factor of 0.9 for Bohemian GE and by 1.73 for Russia. This difference in surface area may indicate that Bohemian GE is slightly more ground than Glauconite from Villers-sur-Mer and much more than Russia GE. The same procedure can be 
applied to the gypsum group (France GE, Sennelier GE, Brenticano GE and Nicosie GE). By taking France GE as reference, the multiplication factors are 0.9 for Sennelier GE, 1.1 for Brentonico GE and 2.4 for Nicosie GE.

One appealing aspect to the use of NMR relaxometry is that clear differences appear between glauconite-rich and celadonite-rich materials whereas distinguishing between these two species by standard characterization methods is highly difficult [48]. Clearly, relaxivity profiles corresponding to glauconite-rich materials are significantly lower than all those corresponding to celadonite-rich samples. This observation can surely be assigned to differences in $\mathrm{Fe}^{\mathrm{III}}$ content - an important source of NMR relaxation - in both minerals, celadonite containing more $\mathrm{Fe}^{\mathrm{III}}$ than glauconite. As an illustration, $\mathrm{Fe}^{\mathrm{III}}$ concentrations are $3.05 \mathrm{~mol} \%$ in Cyprus GE compared to $2.52 \mathrm{~mol} \%$ in Bohemian GE [11]. Furthermore, the shape of the NMR relaxation profile typifies the difference in the interaction of water ${ }^{1} \mathrm{H}$ and $\mathrm{Fe}^{\mathrm{III}}$. For instance, the increase of the relaxivity above $20 \mathrm{MHz}$ well observable in the profiles of group (b) that yields a maximum around $60 \mathrm{MHz}$ (beyond the accessible frequency range of the FFC NMR relaxometer) is characteristic of the relaxation induced by $\mathrm{Fe}^{\mathrm{III}}$ directly bound to water molecules [49]. Hence, the difference of NMR profile shapes expresses a difference of accessibility of water to $\mathrm{Fe}^{\mathrm{III}}$ between celadonite and glauconite that originates from the difference of the particle shape of the minerals. The SEM and TEM images of these two GE at several magnifications illustrate this fact (Figure 4). Strikingly, the cuboid shape is more clearly defined for celadonite/Cyprus GE than for glauconite/Bohemian GE. Furthermore, at very high magnification where the lamellar stacking can be well analysed more stacking defects can be observed in the glauconite/Bohemian GE. The influence of this on the shape of NMR profiles will be detailed in further sections.

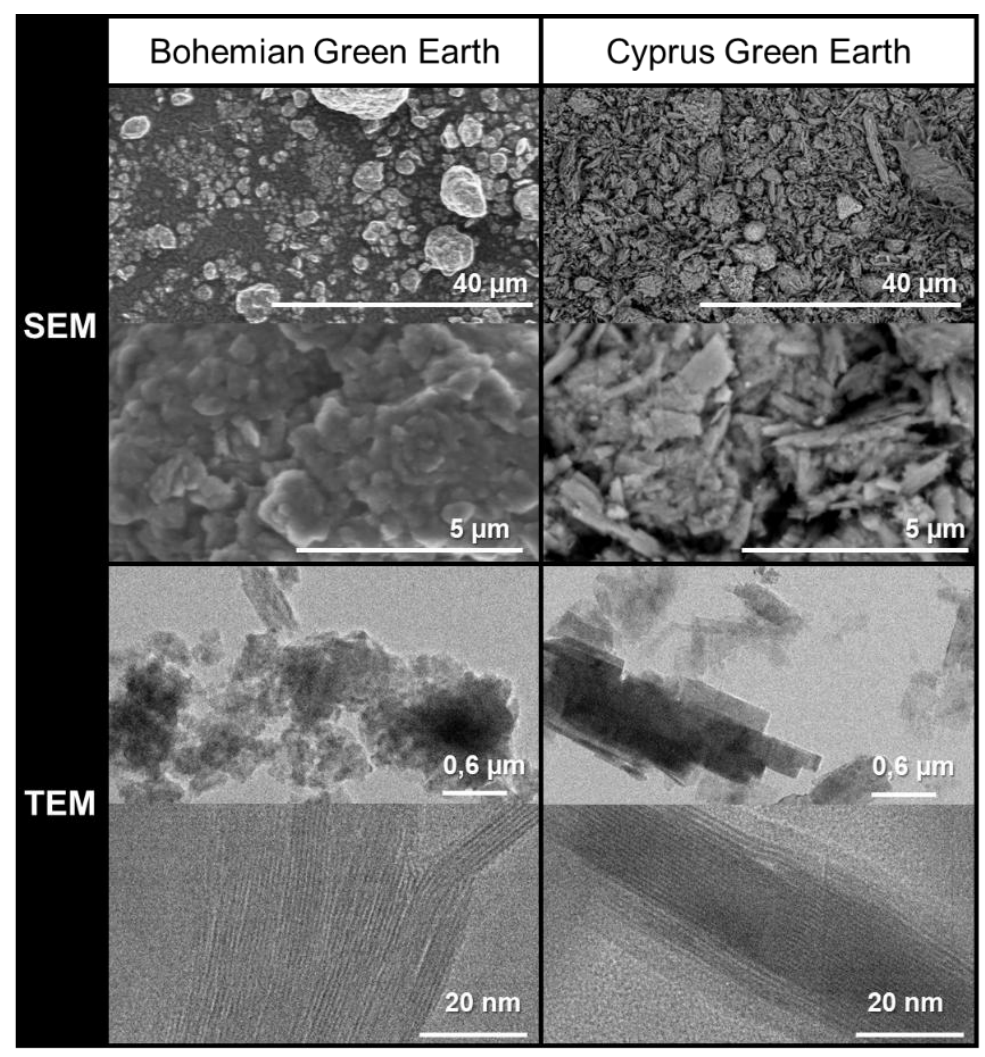

Figure 4: SEM and TEM images of Bohemian GE and Cyprus GE at different scales. 


\section{Revealing dynamics at different scales.}

To understand the interaction of water molecules with the minerals used in this study, it is important to model NMR relaxation profiles with physical and chemical parameters of the minerals. As an illustration, this modelling exercise will be carried out on GE Bohemia and GE Cyprus that are glauconite-rich and celadonite-rich, respectively. At this stage, it is important to describe more precisely their structure in order to build an appropriate model for ${ }^{1} \mathrm{H}$ NMR relaxation. Celadonite and glauconite are phyllosilicates, that both belong to the mica group. They consist in sheets that are formed by an aluminium oxide octahedral layer sandwiched between two silicon oxide tetrahedral layers. Depending on formation conditions and ore deposit environment, atomic substitutions can occur in both the tetrahedral and octahedral layers. In the octahedral layer, $\mathrm{Al}^{\mathrm{III}}$ can be replaced by $\mathrm{Fe}^{\mathrm{III}}, \mathrm{Fe}^{\mathrm{II}}$ or $\mathrm{Mg}^{\mathrm{II}}$ whereas in the tetrahedral layer, silicon can be replaced by $\mathrm{Al}^{\mathrm{III}}$ or $\mathrm{Fe}^{\mathrm{III}}$. The rate of substitutions differs between these two minerals. In pure celadonite, substitutions occur mostly in the octahedral layer. The Si substitution rate is higher in glauconite than in celadonite and the celadonite $\mathrm{R}^{\mathrm{II}}: \mathrm{R}^{\mathrm{III}}$ ratio is around $1: 1$ while in glauconite, it is about 1:2 [9]. $\mathrm{Fe}^{\mathrm{III}}$ substitution significantly affects $\mathrm{NMR}$ properties, as the paramagnetism of $\mathrm{Fe}^{\mathrm{III}}$ strongly enhances the relaxation of the surrounding nuclei. Furthermore, in micas that are highly charged and with $\mathrm{K}^{+}$as interlayer cation, water molecules cannot enter the interlayer space. Consequently, as far as NMR relaxation modelling is concerned, both minerals can be simplified as cuboids with 2 extended faces (sheet packs) with paramagnetic centres distributed on both basal and edge surfaces (see Figure 5). The interaction between water molecules and the paramagnetic centres on basal surfaces will clearly differ from those on edge sites in terms of distance between the water spins and the paramagnetic sites. These two types of sites will then yield different relaxation frequency dependence as detailed in the following.

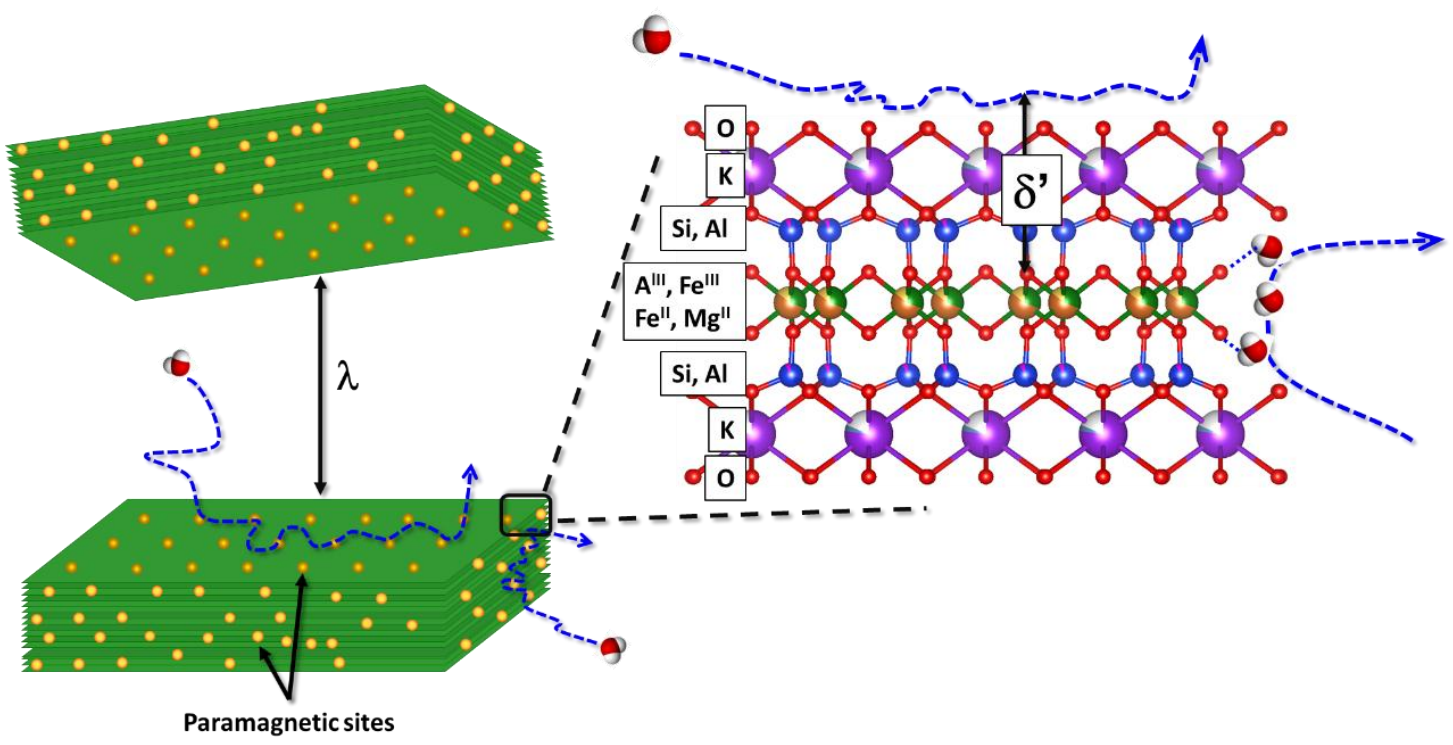

Figure 5: schematic representation of water dynamics and interactions with the phyllosilicates.

As shown in previous sections, water molecules interacting with the mineral surface and with other water molecules in bulk environment are in fast exchange. Consequently, the relaxation rate can be expressed as a linear combination of the relaxation rate caused by the surface $R_{1, \operatorname{surf}}\left(\omega_{0}\right)$ and the relaxation rate in the bulk environment $R_{1, \text { vol }}\left(\omega_{0}\right)$ [29]: 
$R_{1}\left(\omega_{0}\right)=\frac{1}{T_{1}\left(\omega_{0}\right)}=R_{1, v o l}+\frac{N_{S}}{N} R_{1, \operatorname{surf}\left(\omega_{0}\right)}$

$R_{1, v o l}\left(\omega_{0}\right)$ is mainly driven by fast molecular motions such as rotation and translation. The contribution of the paramagnetic oxygen must be also considered. These contributions are constant over the whole frequency range explored here. In consequence, $R_{1, v o l}\left(\omega_{0}\right)$ is constant with frequency and is about $0.3 \mathrm{~s}^{-1}$ [41]. On the contrary, the relaxation rate caused by the surface $R_{1, \text { surf }}\left(\omega_{0}\right)$ is highly dependent on frequency. Its contribution to the global relaxation rate $R_{1}\left(\omega_{0}\right)$ is modulated by $N_{\mathrm{S}} / N$, the fraction of water molecules interacting with the surface over the total number of water molecules.

The expression of $R_{1, \text { surf }}\left(\omega_{0}\right)$ has been previously derived for dilute aqueous dispersions of synthetic clays (saponite [50] and laponite [51]). These associated models based on Reorientation Mediated by Translational Diffusion (RMTD) [50] for saponite and Brownian flight [51] for laponite cannot be applied to the case of GE materials. Indeed, in contrast with synthetic saponite and laponite, natural minerals such as GE samples contain significant amounts of paramagnetic species, which calls for a different model. As already pointed out, there are two types of $\mathrm{Fe}^{\mathrm{III}}$ that cannot be treated identically. Indeed, on the edge surface, water molecules can be directly bound to iron $(\mathrm{Fe}-\mathrm{O}-\mathrm{H})$ while on the basal surface iron is buried within the structure. In consequence, the term surface $R_{1, \text { surf }}\left(\omega_{0}\right)$ has to be split into two terms noted $R_{1, F e H}\left(\omega_{0}\right)$ for the case of water transiently fixed to iron site and $R_{1,2 D}\left(\omega_{0}\right)$ for water interacting with the basal surface.

The case of water interacting directly with paramagnetic ions in solutions has been largely treated in literature [52], [53], [54], [55]. From the early works of Solomon [56], Bloembergen and Morgan [57] leading to the theory named as SBM, several improvements have been performed by different groups in order to solve problems linked to the approximations made in the SBM theory. In this regard, a detailed comparison of the different approaches has been carried out by Belorizky et al. [58]. Nevertheless, all these advanced theories deal with paramagnetic ions or complexes in solutions and the case of paramagnetic ions fixed on surface has not been treated yet. Moreover, these theories require numerical calculations. To approach this case in a simplified way, we start from the equation of the SBM model and limit the number of associated parameters. Hence $R_{1, F e H}\left(\omega_{0}\right)$ can be expressed as:

$$
R_{1, \mathrm{FeH}}\left(\omega_{0}\right)=\frac{1}{T_{1, \mathrm{FeH}}\left(\omega_{0}\right)}=\frac{2}{15}\left(\frac{\gamma_{I} \gamma_{S} \hbar}{\delta \prime^{3}}\right)^{2} S(S+1)\left\{\frac{3 \tau_{c 1}}{1+\omega_{I}^{2} \tau_{c 1}^{2}}+\frac{7 \tau_{c 2}}{1+\omega_{S}^{2} \tau_{c 2}^{2}}\right\}
$$

where $\gamma_{\mathrm{I}}$ and $\gamma_{\mathrm{S}}$ are the gyromagnetic ratio of ${ }^{1} \mathrm{H}$ and electron respectively and $S$ the spin number of the paramagnetic species (for $\mathrm{Fe}^{\mathrm{III}} S=5 / 2$ ). Water molecules are in the ligand field of $\mathrm{Fe}^{\mathrm{III}}$ ion yielding a minimal approach distance $\delta$ " about $0.3 \mathrm{~nm}$. The correlation times $\tau_{\mathrm{c} 1}$ and $\tau_{\mathrm{c} 2}$ depend on the exchange time $\tau_{\text {exch }}$ and the electronic relaxation times $T_{1, \text { elec }}\left(\omega_{S}\right)$ and $T_{2, \text { elec }}\left(\omega_{S}\right)$ according to:

$\frac{1}{\tau_{c 1}}=\frac{1}{\tau_{\text {exch }}}+\frac{1}{T_{1, \text { elec }}\left(\omega_{S}\right)}=\frac{1}{\tau_{\text {exch }}}+\frac{1}{5} H_{S}^{2} \tau_{v}\left\{\frac{1}{1+\omega_{S}^{2} \tau_{v}^{2}}+\frac{4}{1+4 \omega_{S}^{2} \tau_{v}^{2}}\right\}$

$\frac{1}{\tau_{c 2}}=\frac{1}{\tau_{\text {exch }}}+\frac{1}{T_{2, \text { elec }}\left(\omega_{S}\right)}=\frac{1}{\tau_{\text {exch }}}+\frac{1}{10} H_{S}^{2} \tau_{v}\left\{3+\frac{5}{1+\omega_{S}^{2} \tau_{v}^{2}}+\frac{2}{1+4 \omega_{S}^{2} \tau_{v}^{2}}\right\}$

In this theory, the frequency dependence of $T_{1, \text { elec }}$ and $T_{2, \text { elec }}$ arises from the fluctuations of electronic spin in the $z$ direction occurring due to vibrations of the lattice that yields fluctuations of the dipolar interaction between ${ }^{1} \mathrm{H}$ water molecules bound to $\mathrm{Fe}{ }^{\mathrm{III}}$ ions. $H_{S}$ and $\tau_{v}$ are the amplitude and the correlation time associated to these vibrations, respectively. 
The case of water interacting with a flat surface containing paramagnetic sites has been treated by Barberon et al. [59], Korb et al.[60] and $R_{1,2 D}\left(\omega_{0}\right)$ can be expressed using their model:

$R_{1,2 D}\left(\omega_{0}\right)=\frac{1}{T_{1,2 D}\left(\omega_{0}\right)}=\frac{\pi}{15} \frac{\sigma_{S}}{\left(\lambda \delta^{\prime}\right)^{2}}\left(\gamma_{I} \gamma_{S} \hbar\right)^{2} S(S+1) \times \tau_{m}\left\{3 \ln \left[\frac{1+\omega_{I}^{2} \tau_{m}^{2}}{\left(\tau_{m} / \tau_{S}\right)^{2}+\omega_{I}^{2} \tau_{m}^{2}}\right]+7 \ln \left[\frac{1+\omega_{S}^{2} \tau_{m}^{2}}{\left(\tau_{m} / \tau_{S}\right)^{2}+\omega_{S}^{2} \tau_{m}^{2}}\right]\right\}$

In equation $5, \delta^{\prime}$ is the minimal approach distance (sketched on figure 5 ) between water protons (spin $I=1 / 2$ ) and the electronic spin of $\mathrm{Fe}^{\mathrm{III}}(S=5 / 2), \tau_{m}$ the correlation time of translational diffusion and $\tau_{S}$ the residence time of water on the phyllosilicate basal surface $\left(\tau_{S} \gg \tau_{m}\right.$ ). The ratio $A=\tau_{S} / \tau_{m} \rightarrow \infty$ represents the average number of steps of water at the surface and can be defined as the surface dynamical affinity or the "NMR wettability". Finally, $\omega_{\mathrm{I}}$ and $\omega_{\mathrm{S}}=658 \omega_{\mathrm{I}}$ are the Larmor frequencies of ${ }^{1} \mathrm{H}$ water and $\mathrm{Fe} \mathrm{III}^{\mathrm{III}}$ electron, respectively. Note that there is a factor 2 between this equation and the one given in [59], because here one cuboid has 2 faces, while in [59] only one surface has been considered.

Finally, one has to set the contributions of each of these terms that are related to the number of water molecules interacting with the different sites.

$R_{1}\left(\omega_{0}\right)=R_{1, v o l}+\frac{N_{S}}{N} R_{1,2 D}\left(\omega_{0}\right)+\frac{N_{F e}}{N} R_{1, F e H}\left(\omega_{0}\right)$

The proportion of water population interacting with the surface is given by [59]:

$\frac{N_{S}}{N}=\lambda S_{P, N M R} \rho_{\text {water }}$

With $\lambda$ the thickness of water layers affected by the basal surface between two platelets, $S_{P, N M R}$ the basal surface experienced by water molecule and the water density $\rho_{\text {water }}=1 \mathrm{~g} / \mathrm{cm}^{3}$. It is important to understand that it is not equal to the surface determined by other techniques such as gas adsorption.

The proportion of water population bound to $\mathrm{Fe}^{\mathrm{III}}$ can be expressed as:

$\frac{N_{F e}}{N}=\frac{N_{F e}}{N} \frac{N}{N_{S}}=n \varepsilon^{2} \sigma_{S} \lambda S_{P, N M R} \rho_{w a t e r}$

with $n$ the number of water molecules in the ligand field of $\mathrm{Fe}^{\mathrm{III}}, \varepsilon$ the diameter of water molecule and $\sigma_{S}$ the surface density of $\mathrm{Fe}^{\mathrm{III}}$.

Combining these equations, NMRD profiles of Bohemian GE and Cyprus GE can be both fitted as illustrated in Figure 6 for the volume fraction $\Phi_{V}=0.26$. The corresponding fit parameters are gathered in Table 3. The diameter of water molecule $\varepsilon$, the number of water molecules in the ligand field of $\mathrm{Fe}^{\mathrm{III}} n$, the minimal distance between water and $\mathrm{Fe}^{\mathrm{III}} \delta^{\prime}$ were simply determined from geometrical considerations. Moreover, it is important to stress that most of them only affect the amplitude of the relaxation but not the shape of the profile, which is determined by the physical phenomenon at play. As a result, only the parameters related to the frequency can modify the shape of the profile, namely the characteristic times.

Prior to discussing these values, it is important to check that they are consistent for all volume fractions and provide consistent experienced surfaces $S_{P, N M R}$. The fits and the experienced surfaces for Bohemian and Cyprus GE are plotted in Figure 7 for all $\Phi_{V}$. An important confirmation of the reliability of the procedure is the linear dependence of $S_{P, N M R}$ on pigment concentration, as expected by the results presented in the first section. $S_{P, N M R}$ is 
slightly larger for Cyprus GE than for Bohemian GE, with higher $S_{P, N M R}$ for the basal surface than the edge surface in agreement with the less lamellar shape observed on TEM images (Figure 4). The specific surface area has also been measured for these two pigments using $\mathrm{N}_{2}$ adsorption (see supplementary materials). The slightly higher value for Bohemian GE $\left(63 \mathrm{~m}^{2} / \mathrm{g}\right)$ than for Cyprus GE $\left(57 \mathrm{~m}^{2} / \mathrm{g}\right)$ seems at first sight to contradict our results. Nevertheless, it must be underlined that $S_{P, N M R}$ actually represents the surface interacting with mobile water contrary to gas adsorption technique and differences in specific surface often occurs depending on the method used for its determination especially for swelling clays [61],[62]. More interestingly, the higher $S_{P, N M R}$ of Cyprus GE compared with that of Bohemian GE is in line with the macroscopic aspect of the samples. For a given $\Phi_{V}$, mixtures with Cyprus GE are pastier than those with Bohemian GE, i.e. there is a better swelling of water by Cyprus GE than by Bohemian GE. From our findings, it is reasonable to think that this difference does not only originate from the variation of montmorillonite content between these two pigments but that the multiscale structural aspects could also play a significant role. The correlation between rheological properties and morphological aspects was already pointed out for illite, kaolinite and montmorillonite [63]. 
Table 3: list of parameters used for fitting the NMRD profiles of GE.

\begin{tabular}{|c|c|c|c|c|}
\hline & \multicolumn{2}{|c|}{ Bohemian GE } & \multicolumn{2}{|c|}{ Cyprus GE } \\
\hline & Basal surface & Edge surface & Basal surface & Edge surface \\
\hline$\eta=$ number of $\mathrm{Fe}^{\mathrm{III}} / \mathrm{g}$ of $\mathrm{GE}$ & $16 \times 10^{19}$ & & $20 \times 10^{19}$ & \\
\hline$\sigma_{\mathrm{S}}=$ number of $\mathrm{Fe}^{\mathrm{III}} / \mathrm{cm}^{2}$ of $\mathrm{GE}$ & $2.61 \times 10^{14}$ & $6.2610^{13}$ & $2.65 \times 10^{14}$ & $6.36 \times 10^{13}$ \\
\hline$\varepsilon=$ diameter of water molecule $(\mathrm{nm})$ & 0.3 & - & 0.3 & - \\
\hline $\mathrm{n}=$ number of water molecules per $\mathrm{Fe}^{\mathrm{III}}$ (edge surface) & 1 & 1 & 1 & 1 \\
\hline$\lambda^{\prime}=$ thickness of water between two platelets (nm) & 100 & & 100 & \\
\hline$\tau_{\mathrm{v}}(\mathrm{s})$ & - & $1.30 \times 10^{-11}$ & - & $0.4 \times 10^{-11}$ \\
\hline $\mathrm{H}_{\mathrm{S}}^{2}\left(\mathrm{~s}^{-2}\right)$ & - & $(2 \pi)^{2} 7 \times 10^{19}$ & - & $(2 \pi)^{2} 8 \times 10^{19}$ \\
\hline$\tau_{\text {exch }}(p s)$ & - & 70 & - & 70 \\
\hline$\delta^{\prime}=$ minimal distance between water and $\mathrm{Fe}^{\mathrm{III}}(\mathrm{nm})$ & 0.5 & 0.3 & 0.5 & 0.3 \\
\hline wettability $\tau_{\mathrm{S} / \tau_{\mathrm{m}}}$ & $\infty$ & & $\infty$ & \\
\hline$\tau_{\mathrm{m}}(\mathbf{s})$ & $0.345 \times 10^{-9}$ & & $0.65 \times 10^{-9}$ & \\
\hline $\mathbf{R}_{1, \mathrm{vol}}\left(\mathrm{s}^{-1}\right)$ & 0.25 & & 0.25 & \\
\hline
\end{tabular}
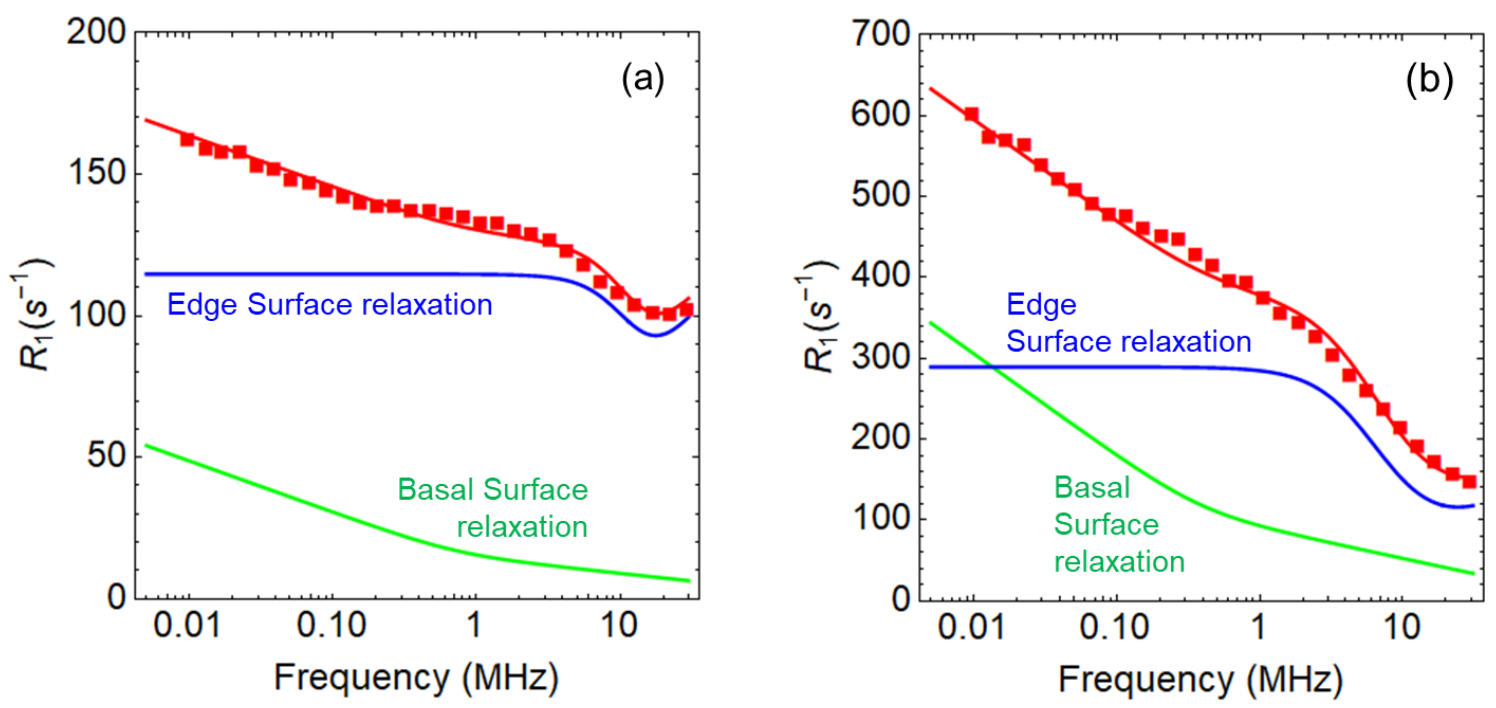

Figure 6. Experimental NMR relaxation profiles (symbol) of Bohemian GE (a) and Cyprus GE (b) with the best fit (red line) for $\Phi_{V}=0.27$. The contributions to relaxation of the basal surface (green line) and of the edge surface (blue line) are also plotted.

The first salient point is the difference in contribution of the basal and edge surfaces between Bohemian and Cyprus GE. The edge surface plays a much more important role for Bohemian GE, i.e. for glauconite. This finding agrees with the level of structural disorder between these two phyllosilicates as illustrated with the SEM and TEM pictures (Figure 4). Celadonite generally exhibits higher basal surface and less lamellar shape than glauconite. In consequence, the ratio of $\mathrm{Fe}^{\mathrm{III}}$ number experienced by water molecules between basal surface and edges is higher for celadonite than for glauconite. Furthermore, the substitution rate is higher for this mineral. This structural disorder also modifies the electronic relaxation times and the related parameters $\left(\mathrm{H}_{\mathrm{S}}\right.$ and $\left.\tau_{\mathrm{v}}\right)$ as they originate from the vibrational properties of the crystal network. Even if the differences are small, they appear higher for glauconite compared to celadonite. 

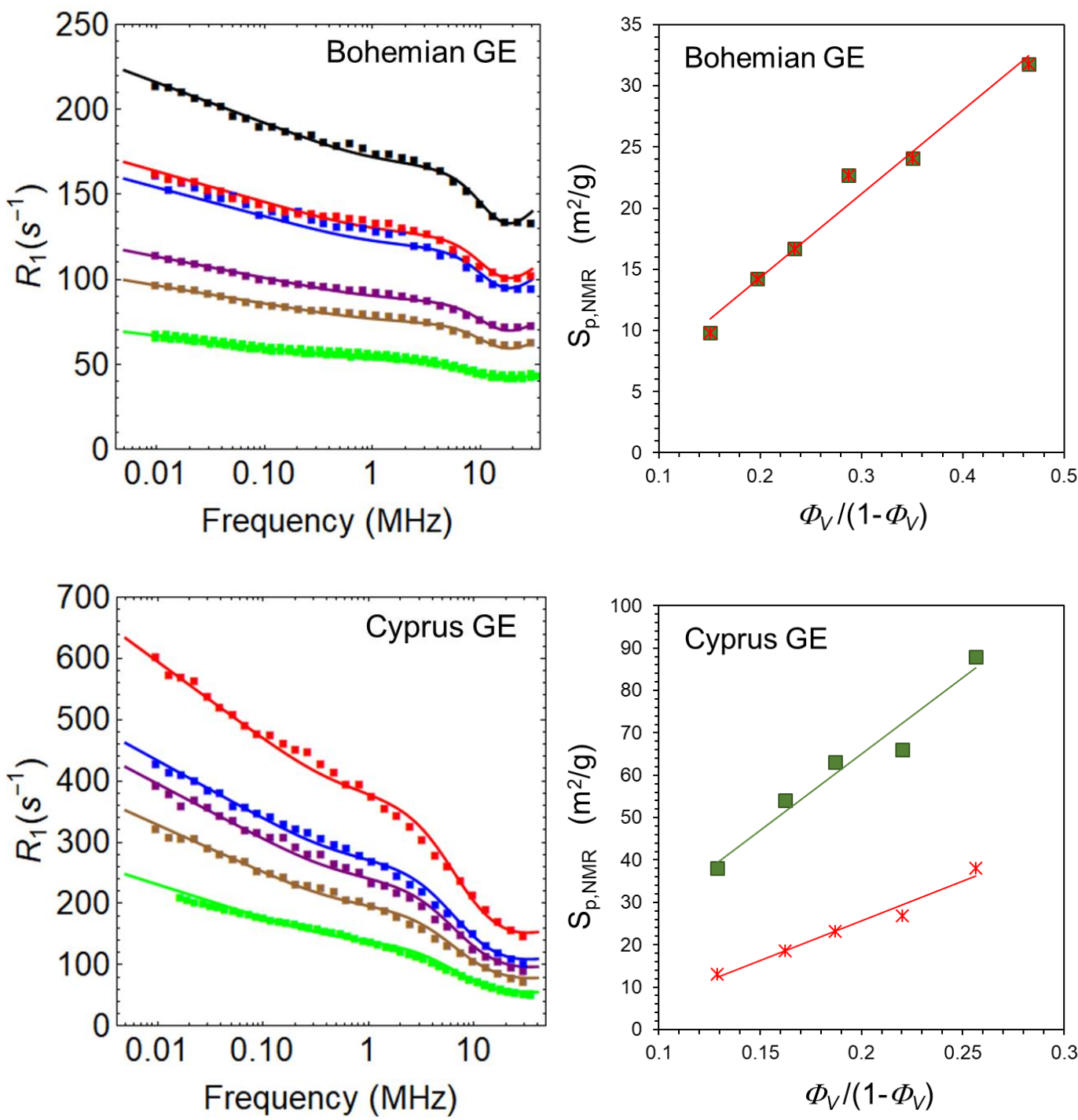

Figure 7. Best fits (plain line) on the experimental NMR relaxation profiles (symbol) of Bohemian GE (top left) and Cyprus GE (bottom left) for several volume fraction of pigments: 0.13 (green), 0.18 (brown), 0.21 (purple), 0.26 (blue), 0.27 (red) and 0.33 (black). Specific surface of the basal plan (green square) and of the edge surface (red star) deduced from the fitting as function of water content for Bohemian GE (top right) and Cyprus GE (bottom right).

The self-diffusion coefficient of water on the basal surface $D_{\text {surf }}$ of the clay can also be evaluated using $D_{\text {surf }}=$ $\frac{\varepsilon^{2}}{4 \tau_{m}}$. Using such a formula, values of $0.25 \times 10^{-6} \mathrm{~cm}^{2} / \mathrm{s}$ and $0.75 \times 10^{-6} \mathrm{~cm}^{2} / \mathrm{s}$ are obtained for Bohemian $\mathrm{GE}$ and Cyprus GE, respectively.

The temperature dependence has been also investigated as it can provide relevant insight into the nature of relaxation processes [64],[65],[66]. NMR relaxation profiles obtained for temperatures ranging from 293 to $318 \mathrm{~K}$ are displayed in supplementary information (figure S5). The decrease of the relaxation rate observed with increasing temperature is typical of a diffusing liquid due to the decrease of the correlation times. However Bohemian GE and Cyprus GE exhibit different behaviours. Whereas for Bohemian GE, the whole profile is slightly shifted to lower values with increasing temperature, the Cyprus GE profile is mainly affected in the low frequency range that shifts toward lower values. Such a finding somehow strengthens the proposed model. Indeed, 
temperature variation impacts more strongly $R_{1,2 D}\left(\omega_{0}\right)$ through the residence time $\tau_{S}$ and the translational time $\tau_{m}$ as compared with $R_{1, \text { FeH }}\left(\omega_{0}\right)$ for which only $\tau_{\text {exch }}$ is affected and $\tau_{\text {exch }} \gg T_{1,2 e l e c}\left(\omega_{S}\right)$. As the contribution of $R_{1,2 D}\left(\omega_{0}\right)$ that affects the low frequency region is much more important for Cyprus GE than for Bohemian GE (Figure 6), temperature variation affects more the NMR relaxation profile of Cyprus GE, especially at low frequency.

\section{Effect of clay swelling on the GE pigments properties}

In order to investigate the effect of clay swelling on the dynamical properties of the GE pigments, we produced a series of mixtures of GE Bohemian and Na-Montmorillonite. As already detailed in the first section, the natural Na-Montmorillonite interlayer distance extends linearly with the amount of water until full delamination. The modelling was first carried out for three hydration states for the synthetic Na-Montmorillonite alone. In a second step, mixtures with GE were considered. The synthetic Na-Montmorillonite does not carry any Fe ${ }^{\mathrm{III}}$, which results in lower relaxation rates compared with GEs. Another consequence is that the model developed for GEs cannot be applied. On the contrary, the model based on the intermittence of water diffusing partially on the clay surface and partially in the bulk environment [67] seems more suitable and has been validated on plaster (gypsum paste) [68] and laponite [51]. From this model, we use the asymptotic expression valid for flat surfaces.

$$
R_{1, \text { surf }}\left(\omega_{0}\right) \propto\left[\left(\frac{\omega_{0}}{\omega_{A}}\right)^{\frac{1}{2}}+\frac{\omega_{0}}{\omega_{A}}+\frac{1}{2}\left(\frac{\omega_{0}}{\omega_{A}}\right)^{\frac{3}{2}}\right]^{-1}+4\left[\left(\frac{2 \omega_{0}}{\omega_{A}}\right)^{\frac{1}{2}}+\frac{2 \omega_{0}}{\omega_{A}}+\frac{1}{2}\left(\frac{2 \omega_{0}}{\omega_{A}}\right)^{\frac{3}{2}}\right]^{-1}
$$

With $\omega_{A}=\frac{\varepsilon^{2}}{2 D \tau_{A}^{2}}$ and where $\tau_{\mathrm{A}}$ is the average adsorption time on the surface and $\varepsilon$ is the order of the thickness of the adsorption layer. Note that in this case where no paramagnetic centres are present, the determination of the absolute value of $R_{1, \text { surf }}\left(\omega_{0}\right)$ is trickier because it requires the knowledge of the dynamical orientation of water molecules with respect to the surface. Here, the interesting parameter being the average adsorption time $\tau_{\mathrm{A}}$, this problem has been let aside for future work. The fit results are displayed in Figure 8. The fits are reasonably good provided the use of relatively high value of $R_{1, v o l}\left(\omega_{0}\right)$ about $2 \mathrm{~s}^{-1}$. The present model does not capture all the dynamical processes in the system, particularly when the distance between two surfaces is small.

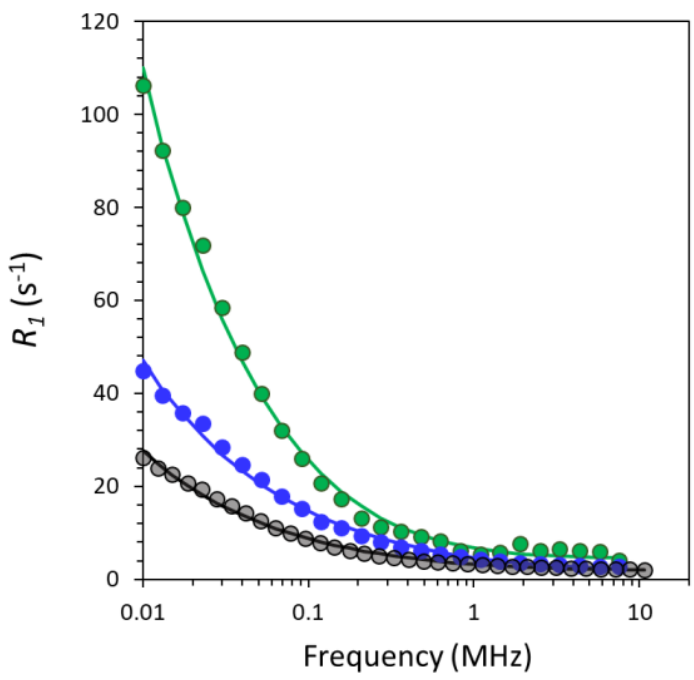


Figure 8. Experimental NMR relaxation profiles (symbol) of Na-Montmorillonite with the best fits (plain lines) for three clay volume fractions: 0.36 (green), 0.26 (blue) and 0.15 (black).

The fitting parameter is $\omega_{A}$ while the relevant value is actually the residence time $\tau_{A}$. The water self-diffusion coefficient is taken at $2 \times 10^{-9} \mathrm{~m}^{2} / \mathrm{s}$, a value between bulk value for water $\left(2.25 \times 10^{-9} \mathrm{~m}^{2} / \mathrm{s}\right)$ [69], and the value determined by neutron Time-of-Flight $\left(1 \times 10^{-9} \mathrm{~m}^{2} / \mathrm{s}\right)$ and Spin Echo $\left(0.5 \times 10^{-9} \mathrm{~m}^{2} / \mathrm{s}\right)$ experiments for water confined in bi-hydrated Na-montmorillonite [70]. The layer $\varepsilon$ is approximately equal to the diameter of the water molecule, i.e. $0.3 \mathrm{~nm}$. Hence, the residence time $\tau_{A}$ of water molecule on the montmorillonite surface spans approximately from 1 to $3 \mathrm{~ns}$ for a volume fraction $\Phi_{V}$ in the range of $15 \%$ to $36 \%$. These values are in good agreement with those found in other phyllosilicates [51],[67].

The NMR relaxivity profiles of Bohemian GE /synthetic Na-Montmorillonite mixtures are presented in Figure 9. The total phyllosilicate volume fraction $\Phi_{V}$ is kept constant at $13 \%$ and only the proportion of the two types of phyllosilicates is varied. The profile progressively changes from the one of neat Na-Montmorillonite to neat Bohemian GE upon the addition of the latter. The salient point is that the profile of the mixtures can be simply recovered by the linear combination of the two individual profiles, i.e.

$$
r_{1}^{\text {mixture }}=\alpha r_{1}^{\text {Bohemian } G E}+(1-\alpha) r_{1}^{\text {montmorillonite }}
$$

where $\alpha$ is the proportion of Bohemian GE in the mixture (Figure 9). Similarly, the best fits are obtained using the same parameters as those used for each phyllosilicate alone. On one hand, it indicates that the mixtures are homogeneous at all scales. On the other hand, no additional dynamical feature occurs at the mesoscopic scale while the texture and the macroscopic rheological properties of the dispersion are significantly changing. Indeed, adding more Na-Montmorillonite leads to a pastier paint. Such a conclusion could be slightly mitigated considering that the swelling properties of synthetic Na-montmorillonite are different from those of natural $\mathrm{Na}$ montmorillonite [71]. In particular, its gelling properties are significantly impaired.

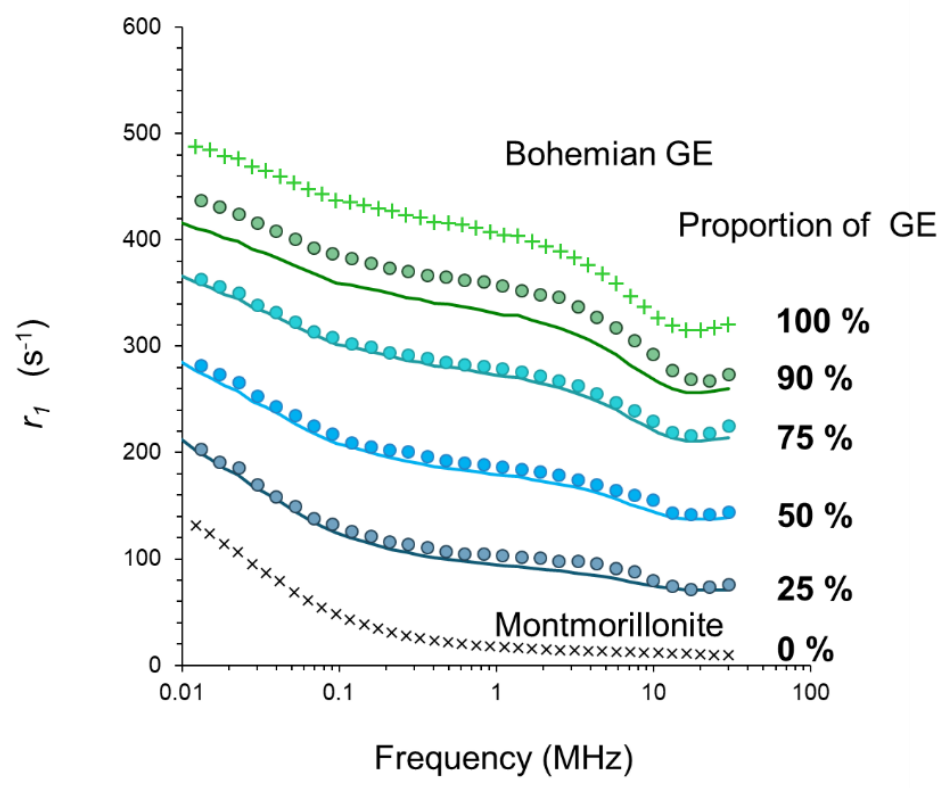


Figure 9. ${ }^{1} H$ NMR Relaxivity $r_{I}=R_{I} /\left(\Phi_{V} /\left(1-\Phi_{V}\right)\right)$ profiles of water in Bohemian $G E+$ montmorillonite mixtures for proportions of Bohemian GE ranging from $0 \%$ to $100 \%$ at a given $\Phi_{V}$. The symbols represent the experimental data and the lines represent the linear combinations of montmorillonite and Bohemian $G E$ relaxivities.

\section{Conclusion}

Probing the quality of the dispersions of inorganic particles in solvent is one of the central issues in colloid science. NMR relaxometry at fixed field has proven to be an interesting tool to evaluate the amount of surface experienced by the solvent [17]. However, its accuracy requires the knowledge of the surface relaxivity or of a perfectly defined reference. Here, we used variable field NMR relaxometry. Our approach has been applied on various green earth dispersions. Green earth pigments are natural mineral mixtures mainly composed of phyllosilicates [11],[7]. The theoretical modelling carried out up to now to analyse the NMR relaxometry data were dedicated to synthetic phyllosilicates free from paramagnetic atoms [50],[51]. However, natural phyllosilicates contain paramagnetic species from low to very large amount as in the case of celadonite and glauconite [72]. In consequence, the available models in the literature were not suitable for natural products. In this publication, we have implemented an analytical model allowing to analyse NMR relaxation profiles for such complex systems and to extract characteristic times (diffusion and residence times). In addition, our approach makes it now possible to differentiate the contribution of the basal and the edge surfaces of the phyllosilicates. The surface areas experienced by water were thus deduced without prior detailed knowledge of the surface relaxivity or in the absence of a perfectly defined reference. They were found to be in line with the macroscopic texture of the mixtures (pasty/liquid). This finding open important perspectives in clay dispersion science, as it could give the opportunity to understand why two similar phyllosilicates, here celadonite and glauconite, with approximately the same surface area exhibit significant differences in their rheological properties. For instance, in geoscience, it would help to understand why similar clay formation would behave differently when exposed to water. Furthermore, the NMR relaxation profile appeared to be highly sensitive to the structural aspect of the phyllosilicate and on the accessibility of water to iron. Hence, it is possible to clearly discriminate celadonite from glauconite minerals that are structurally so close that standard techniques struggle to distinguish them [11], [48]. NMR relaxometry could therefore be used as a relevant complementary technique in the identification process of dispersed mineral phases. In this work, the effect of adding to Bohemian GE a swelling phyllosilicate (synthetic Na-montmorillonite) was also studied. The NMR relaxation profiles appeared simply to be the linear combination of the two individual minerals (glauconite and montmorillonite) profiles. One of the aims of this work was to provide sound bases for future studies on tempera paint with its three main components (pigments, binder and water) by analysing in detail the interaction of water with mineral surface and the associated multiscale water dynamics. From this point of view, the results of this work extend beyond the field of cultural heritage, and can be exploited in the various domains where clay/water interaction is of importance. The understanding of the ${ }^{1} \mathrm{H}$ NMR relaxation profiles of water with green earth pigments being achieved, it is now possible to reveal how the binder affects the water dynamics at the microscopic level in tempera paints.

\section{Acknowledgements}

The work of article benefits from the COST Action CA15209 EURELAX "European Network on NMR Relaxometry", supported by COST (European Cooperation in Science and Technology). The authors are indebted 
to the mineral gallery of MNHN for providing some mineral samples. They acknowledge the Institute of Materials of Paris (IMPC) for the access of the NMR relaxometers (RELAXOME facility). Mohamed Selmane and Sandra Casale are gratefully acknowledged for conducting XRD and TEM/SEM experiments, respectively. The NMR relaxometers, the microscopes and the X-ray diffractometer were funded by Sorbonne Université, CNRS and Région Île de France, and is part of The Institute of Materials of Paris (IMPC). The authors are grateful to Eva Balaven, Santiago Braley, Lorie Chahmirian, Augustin Lavirotte, Laura Maiche, Pablo Mas and Pauline Sourd, for their technical help. A.-L. R. acknowledges Laura Scalfi and Étienne Mangaud for the help in writing the fitting python program. This work was supported by the Observatoire des Patrimoines of Sorbonne Université (OPUS).

\section{References}

[1] S. Mukherjee, The science of clays: applications in industry, engineering and environment, 2013. https://search.ebscohost.com/login. aspx?direct=true\&scope=site \&db=nlebk\&db=nlabk\&AN=650362 (accessed March 28, 2020).

[2] F. Wypych, K.G. Satyanarayana, eds., Clay surfaces: fundamentals and applications, 1. ed, Elsevier/Academic Press, Amsterdam, 2004.

[3] D.V. Thompson, C. Cennini, II libro dell'Arte - English translation The Craftsman's Handbook, Courier Corporation, 1954.

[4] C. Cennini, L. Broecke, Cennino Cennini's II Libro dell'arte: a new English translation and commentary with Italian transcription, Archetype, London, 2015.

[5] R. Siddall, Mineral Pigments in Archaeology: Their Analysis and the Range of Available Materials, Minerals. 8 (2018) 201. https://doi.org/10.3390/min8050201.

[6] C. Lofrumento, M. Ricci, L. Bachechi, D. De Feo, E.M. Castellucci, The first spectroscopic analysis of Ethiopian prehistoric rock painting: Spectroscopic analysis of Ethiopian prehistoric rock painting, J. Raman Spectrosc. 43 (2012) 809-816. https://doi.org/10.1002/jrs.3096.

[7] D. Hradil, A. Píšková, J. Hradilová, P. Bezdička, G. Lehrberger, S. Gerzer, Mineralogy of Bohemian green earth pigments and its microanalytical evidence in historical paintings: Mineralogy of Bohemian green earth pigment, Archaeometry. 53 (2011) 563-586. https://doi.org/10.1111/j.1475-4754.2010.00554.x.

[8] D. Hradil, J. Hradilová, P. Bezdička, Clay Minerals in European Painting of the Mediaeval and Baroque Periods, Minerals. 10 (2020) 255. https://doi.org/10.3390/min10030255.

[9] H.A. Buckley, J.C. Bevan, K.M. Brown, L.R. Johnson, V.C. Farmer, Glauconite and celadonite: two separate mineral species, Mineralogical Magazine. 42 (1978) 373-382. https://doi.org/10.1180/minmag.1978.042.323.08.

[10] V.A. Drits, B.B. Zviagina, D.K. McCarty, A.L. Salyn, Factors responsible for crystal-chemical variations in the solid solutions from illite to aluminoceladonite and from glauconite to celadonite, American Mineralogist. 95 (2010) 348-361. https://doi.org/10.2138/am.2010.3300.

[11] A. Fanost, A. Gimat, L. de Viguerie, P. Martinetto, A.-C. Giot, M. Clémancey, G. Blondin, F. Gaslain, H. Glanville, P. Walter, G. Mériguet, A.-L. Rollet, M. Jaber, Revisiting the identification of commercial and historical green earth pigments, Colloids and Surfaces A: Physicochemical and Engineering Aspects. 584 (2020) 124035. https://doi.org/10.1016/j.colsurfa.2019.124035.

[12] Chapter 4 Celadonite, in: Developments in Sedimentology, Elsevier, 1973: pp. 47-53. https://doi.org/10.1016/S0070-4571(09)70007-X.

[13] Chapter 3 Glauconite, in: Developments in Sedimentology, Elsevier, 1973: pp. 25-45. https://doi.org/10.1016/S0070-4571(09)70006-8.

[14] G.S. Odin, ed., Green marine clays: oolitic ironstone facies, verdine facies, glaucony facies and celadonite-bearing facies ; a comparative study, Elsevier, Amsterdam, 1988.

[15] T. Cosgrove, T.M. Obey, Colloidal Systems, in: R.K. Harris (Ed.), Encyclopedia of Magnetic Resonance, John Wiley \& Sons, Ltd, Chichester, UK, 2007: p. emrstm0083.

https://doi.org/10.1002/9780470034590.emrstm0083. 
[16] S.J. Mears, T. Cosgrove, L. Thompson, I. Howell, Solvent Relaxation NMR Measurements on Polymer, Particle, Surfactant Systems, Langmuir. 14 (1998) 997-1001. https://doi.org/10.1021/la970744z.

[17] C.L. Cooper, T. Cosgrove, J.S. van Duijneveldt, M. Murray, S.W. Prescott, The use of solvent relaxation NMR to study colloidal suspensions, Soft Matter. 9 (2013) 7211. https://doi.org/10.1039/c3sm51067k.

[18] D. Fairhurst, T. Cosgrove, S.W. Prescott, Relaxation NMR as a tool to study the dispersion and formulation behavior of nanostructured carbon materials: Relaxation NMR for nanostructured carbons, Magn. Reson. Chem. 54 (2016) 521-526. https://doi.org/10.1002/mrc.4218.

[19] A. Paruthi, S.K. Misra, Relaxation time: a proton NMR-based approach as a metric to measure reactivity of engineered nanomaterials, J Nanopart Res. 19 (2017) 292. https://doi.org/10.1007/s11051-0173962-z.

[20] M.R. Hossain, D. Wray, A. Paul, P.C. Griffiths, Probing the surfaces of core-shell and hollow nanoparticles by solvent relaxation NMR, Magn. Reson. Chem. 56 (2018) 251-256. https://doi.org/10.1002/mrc.4707.

[21] T. Ito, C. Kida, K. Okada, J. Ikeda, K. Otomura, Y. Hayashi, Y. Obata, K. Takayama, Y. Onuki, Nondestructive Monitoring of the Dispersion State of Titanium Dioxide Nanoparticles in Concentrated Suspensions Using Magnetic Resonance Imaging, Langmuir. 34 (2018) 12093-12099. https://doi.org/10.1021/acs.langmuir.8b02410.

[22] C. Takai-Yamashita, E. Sato, M. Fuji, NMR as a Tool to Characterize the Aggregation Structure of Silica Nanoparticles in a Liquid, KONA. 37 (2020) 233-243. https://doi.org/10.14356/kona.2020012.

[23] L. Yuan, L. Chen, X. Chen, R. Liu, G. Ge, In Situ Measurement of Surface Functional Groups on Silica Nanoparticles Using Solvent Relaxation Nuclear Magnetic Resonance, Langmuir. 33 (2017) 8724-8729. https://doi.org/10.1021/acs.langmuir.7b00923.

[24] M. Tawfilas, M. Mauri, L. De Trizio, R. Lorenzi, R. Simonutti, Surface Characterization of $\mathrm{TiO}_{2}$ Polymorphic Nanocrystals through ${ }^{1}$ H-TD-NMR, Langmuir. 34 (2018) 9460-9469. https://doi.org/10.1021/acs.langmuir.8b01216.

[25] B.E. Kinn, T.R. Myers, A.M. Allgeier, Surface enhanced nuclear magnetic resonance relaxation mechanisms and their significance in chemical engineering applications, Current Opinion in Chemical Engineering. 24 (2019) 115-121. https://doi.org/10.1016/j.coche.2019.03.010.

[26] L.N. Elliott, R.A. Bourne, A. Hassanpour, J.L. Edwards, S. Sutcliffe, T.N. Hunter, Salt enhanced solvent relaxation and particle surface area determination via rapid spin-lattice NMR, Powder Technology. 333 (2018) 458-467. https://doi.org/10.1016/j.powtec.2018.04.050.

[27] T. Janc, M. Lukšič, V. Vlachy, B. Rigaud, A.-L. Rollet, J.-P. Korb, G. Mériguet, N. Malikova, Ion-specificity and surface water dynamics in protein solutions, Phys. Chem. Chem. Phys. 20 (2018) 30340-30350. https://doi.org/10.1039/C8CP06061D.

[28] R. Kimmich, E. Anoardo, Field-cycling NMR relaxometry, Progress in Nuclear Magnetic Resonance Spectroscopy. 44 (2004) 257-320. https://doi.org/10.1016/j.pnmrs.2004.03.002.

[29] J.-P. Korb, Multiscale nuclear magnetic relaxation dispersion of complex liquids in bulk and confinement, Progress in Nuclear Magnetic Resonance Spectroscopy. 104 (2018) 12-55. https://doi.org/10.1016/j.pnmrs.2017.11.001.

[30] R. Kimmich, NMR Tomography, Diffusometry, Relaxometry, Springer Berlin Heidelberg, Berlin, Heidelberg, 1997. https://doi.org/10.1007/978-3-642-60582-6.

[31] G.J. Churchman, B. Velde, Soil clays: linking geology, biology, agriculture, and the environment, CRC Press, Boca Raton, 2019.

[32] J.S. Whiteley, J.E. Chambers, S. Uhlemann, P.B. Wilkinson, J.M. Kendall, Geophysical Monitoring of Moisture-Induced Landslides: A Review, Rev. Geophys. 57 (2019) 106-145. https://doi.org/10.1029/2018RG000603.

[33] A. Yalcin, The effects of clay on landslides: A case study, Applied Clay Science. 38 (2007) 77-85. https://doi.org/10.1016/j.clay.2007.01.007.

[34] E. Annan, B. Agyei-Tuffour, Y.D. Bensah, D.S. Konadu, A. Yaya, B. Onwona-Agyeman, E. Nyankson, Application of clay ceramics and nanotechnology in water treatment: A review, Cogent Engineering. 5 (2018). https://doi.org/10.1080/23311916.2018.1476017. 
[35] A. Awasthi, P. Jadhao, K. Kumari, Clay nano-adsorbent: structures, applications and mechanism for water treatment, SN Appl. Sci. 1 (2019) 1076. https://doi.org/10.1007/s42452-019-0858-9.

[36] M.K. Uddin, A review on the adsorption of heavy metals by clay minerals, with special focus on the past decade, Chemical Engineering Journal. 308 (2017) 438-462. https://doi.org/10.1016/j.cej.2016.09.029.

[37] M.I. Carretero, Clays in pelotherapy. A review. Part I: Mineralogy, chemistry, physical and physicochemical properties, Applied Clay Science. 189 (2020) 105526. https://doi.org/10.1016/j.clay.2020.105526.

[38] M.I. Carretero, Clays in pelotherapy. A review. Part II: Organic compounds, microbiology and medical applications, Applied Clay Science. 189 (2020) 105531. https://doi.org/10.1016/j.clay.2020.105531.

[39] E. Anoardo, G. Galli, G. Ferrante, Fast-field-cycling NMR: Applications and instrumentation, Applied Magnetic Resonance. 20 (2001) 365-404. https://doi.org/10.1007/BF03162287.

[40] X. Guichet, M. Fleury, E. Kohler, Effect of clay aggregation on water diffusivity using low field NMR, Journal of Colloid and Interface Science. 327 (2008) 84-93. https://doi.org/10.1016/j.jcis.2008.08.013.

[41] J.-P. Korb, Multiscale nuclear magnetic relaxation dispersion of complex liquids in bulk and confinement, Progress in Nuclear Magnetic Resonance Spectroscopy. 104 (2018) 12-55. https://doi.org/10.1016/j.pnmrs.2017.11.001.

[42] P.H. Fries, E. Belorizky, Theory of fast field-cycling NMR relaxometry of liquid systems undergoing chemical exchange, Molecular Physics. 117 (2019) 849-860. https://doi.org/10.1080/00268976.2018.1538539.

[43] D.E. Woessner, An NMR investigation into the range of the surface effect on the rotation of water molecules, Journal of Magnetic Resonance (1969). 39 (1980) 297-308. https://doi.org/10.1016/00222364(80)90138-9.

[44] K. Norrish, Crystalline Swelling of Montmorillonite: Manner of Swelling of Montmorillonite, Nature. 173 (1954) 256-257. https://doi.org/10.1038/173256a0.

[45] K. Norrish, The swelling of montmorillonite, Discuss. Faraday Soc. 18 (1954) 120. https://doi.org/10.1039/df9541800120.

[46] E. Paineau, I. Bihannic, C. Baravian, A.-M. Philippe, P. Davidson, P. Levitz, S.S. Funari, C. Rochas, L.J. Michot, Aqueous Suspensions of Natural Swelling Clay Minerals. 1. Structure and Electrostatic Interactions, Langmuir. 27 (2011) 5562-5573. https://doi.org/10.1021/la2001255.

[47] A. Delville, N. Gasmi, R.J.M. Pellenq, J.M. Caillol, H. Van Damme, Correlations between the Stability of Charged Interfaces and Ionic Exchange Capacity: A Monte Carlo Study, Langmuir. 14 (1998) 5077-5082. https://doi.org/10.1021/la9802872.

[48] J. Duplay, M. Buatier, The problem of differentiation of glauconite and celadonite, Chemical Geology. 84 (1990) 264-266. https://doi.org/10.1016/0009-2541(90)90233-W.

[49] I. Bertini, F. Capozzi, C. Luchinat, Z. Xia, Nuclear and electron relaxation of hexaaquairon(3+), The Journal of Physical Chemistry. 97 (1993) 1134-1137. https://doi.org/10.1021/j100108a006.

[50] T. Zavada, R. Kimmich, J. Grandjean, A. Kobelkov, Field-cycling NMR relaxometry of water in synthetic saponites: Lévy walks on finite planar surfaces, The Journal of Chemical Physics. 110 (1999) 6977-6981. https://doi.org/10.1063/1.478603.

[51] P. Levitz, Random flights in confining interfacial systems, J. Phys.: Condens. Matter. 17 (2005) S4059S4074. https://doi.org/10.1088/0953-8984/17/49/004.

[52] L. Helm, Relaxivity in paramagnetic systems: Theory and mechanisms, Progress in Nuclear Magnetic Resonance Spectroscopy. 49 (2006) 45-64. https://doi.org/10.1016/j.pnmrs.2006.03.003.

[53] I. Bertini, C. Luchinat, G. Parigi, E. Ravera, Solution NMR of paramagnetic molecules: applications to metallobiomolecules and models., 2016.

[54] I. Bertini, C. Luchinat, G. Parigi, E. Ravera, NMR of paramagnetic molecules: applications to metallobiomolecules and models, Second edition, Elsevier, Amsterdam, 2017.

[55] P.H. Fries, E. Belorizky, Relaxation theory of the electronic spin of a complexed paramagnetic metal ion in solution beyond the Redfield limit, The Journal of Chemical Physics. 126 (2007) 204503. https://doi.org/10.1063/1.2730831. 
[56] I. Solomon, Relaxation Processes in a System of Two Spins, Phys. Rev. 99 (1955) 559-565. https://doi.org/10.1103/PhysRev.99.559.

[57] N. Bloembergen, L.O. Morgan, Proton Relaxation Times in Paramagnetic Solutions. Effects of Electron Spin Relaxation, The Journal of Chemical Physics. 34 (1961) 842-850. https://doi.org/10.1063/1.1731684.

[58] E. Belorizky, P.H. Fries, L. Helm, J. Kowalewski, D. Kruk, R.R. Sharp, P.-O. Westlund, Comparison of different methods for calculating the paramagnetic relaxation enhancement of nuclear spins as a function of the magnetic field, The Journal of Chemical Physics. 128 (2008) 052315. https://doi.org/10.1063/1.2833957.

[59] F. Barberon, J.-P. Korb, D. Petit, V. Morin, E. Bermejo, Probing the Surface Area of a Cement-Based Material by Nuclear Magnetic Relaxation Dispersion, Phys. Rev. Lett. 90 (2003) 116103. https://doi.org/10.1103/PhysRevLett.90.116103.

[60] J.-P. Korb, G. Freiman, B. Nicot, P. Ligneul, Dynamical surface affinity of diphasic liquids as a probe of wettability of multimodal porous media, Phys. Rev. E. 80 (2009) 061601. https://doi.org/10.1103/PhysRevE.80.061601.

[61] L.J. Michot, Determination of surface areas and textural properties of clay minerals, in: Developments in Clay Science, Elsevier, 2018: pp. 23-47. https://doi.org/10.1016/B978-0-08-102432-4.00002-0.

[62] F. Macht, K. Eusterhues, G.J. Pronk, K.U. Totsche, Specific surface area of clay minerals: Comparison between atomic force microscopy measurements and bulk-gas (N2) and -liquid (EGME) adsorption methods, Applied Clay Science. 53 (2011) 20-26. https://doi.org/10.1016/j.clay.2011.04.006.

[63] C. Blachier, A. Jacquet, M. Mosquet, L. Michot, C. Baravian, Impact of clay mineral particle morphology on the rheological properties of dispersions: A combined X-ray scattering, transmission electronic microscopy and flow rheology study, Applied Clay Science. 87 (2014) 87-96. https://doi.org/10.1016/j.clay.2013.11.004.

[64] J.L. Major, G. Parigi, C. Luchinat, T.J. Meade, The synthesis and in vitro testing of a zinc-activated MRI contrast agent, Proceedings of the National Academy of Sciences. 104 (2007) 13881-13886. https://doi.org/10.1073/pnas.0706247104.

[65] P. Caravan, G. Parigi, J.M. Chasse, N.J. Cloutier, J.J. Ellison, R.B. Lauffer, C. Luchinat, S.A. McDermid, M. Spiller, T.J. McMurry, Albumin Binding, Relaxivity, and Water Exchange Kinetics of the Diastereoisomers of MS-325, a Gadolinium(III)-Based Magnetic Resonance Angiography Contrast Agent, Inorg. Chem. 46 (2007) 6632-6639. https://doi.org/10.1021/ic700686k.

[66] J.-P. Korb, M. Whaley-Hodges, R.G. Bryant, Translational diffusion of liquids at surfaces of microporous materials: Theoretical analysis of field-cycling magnetic relaxation measurements, Phys. Rev. E. 56 (1997) 1934-1945. https://doi.org/10.1103/PhysRevE.56.1934.

[67] P. Levitz, Chapter 12. Interfacial and Intermittent Dynamics of Water in Colloidal Systems as Probed by Fast Field-cycling Relaxometry, in: R. Kimmich (Ed.), New Developments in NMR, Royal Society of Chemistry, Cambridge, 2018: pp. 303-321. https://doi.org/10.1039/9781788012966-00303.

[68] J.-P. Korb, P.E. Levitz, M.D. Hürlimann, Y.Q. Song, P. Fantazzini, V. Bortolotti, Direct Probing of the Wettability of Plaster Pastes at the Nanoscale by Proton Field Cycling Relaxometry, in: AIP Conference Proceedings, AIP, Cambridge (Massachusetts), 2008: pp. 55-58. https://doi.org/10.1063/1.3058546.

[69] R. Mills, Self-diffusion in normal and heavy water in the range 1-45.deg., J. Phys. Chem. 77 (1973) 685688. https://doi.org/10.1021/j100624a025.

[70] N. Malikova, A. Cadéne, V. Marry, E. Dubois, P. Turq, J.-M. Zanotti, S. Longeville, Diffusion of water in clays - microscopic simulation and neutron scattering, Chemical Physics. 317 (2005) 226-235. https://doi.org/10.1016/j.chemphys.2005.04.035.

[71] L. Le Forestier, F. Muller, F. Villieras, M. Pelletier, Textural and hydration properties of a synthetic montmorillonite compared with a natural $\mathrm{Na}$-exchanged clay analogue, Applied Clay Science. 48 (2010) 18-25. https://doi.org/10.1016/j.clay.2009.11.038.

[72] H.A. Buckley, J.C. Bevan, K.M. Brown, L.R. Johnson, V.C. Farmer, Glauconite and celadonite: two separate mineral species, Mineral. Mag. 42 (1978) 373-382. https://doi.org/10.1180/minmag.1978.042.323.08. 

Supplementary information in Data in Brief : Green Earth pigments aqueous dispersions: NMR relaxation rates dataset, Agathe Fanost, Maguy Jaber, Jean-Pierre Korb, Pierre E. Levitz, Laurent J. Michot, Guillaume Mériguet, Anne-Laure Rollet, Data in Brief 2020, 32, 106270 (doi.org/10.1016/j.dib.2020.106270).

\section{Green Earth pigments aqueous dispersions: NMR relaxation rates dataset}

\section{Authors}

Agathe Fanost ${ }^{1,2}$, Maguy Jaber ${ }^{2}$, Laurence de Viguerie ${ }^{2}$, Jean-Pierre Korb ${ }^{1}$, Pierre E. Levitz ${ }^{1}$, Laurent J. Michot $^{1}$, Guillaume Mériguet ${ }^{1}$, Anne-Laure Rollet ${ }^{1, *}$

\section{Affiliations}

1. Sorbonne Université, CNRS, laboratoire PHysico-chimie des Electrolytes et Nanosystèmes InterfaciauX, PHENIX, F-75005 Paris, France

2. Sorbonne Université, CNRS, laboratoire d'Archéologie Moléculaire et Structurale, LAMS, F-75005 Paris, France

\section{Corresponding author(s)}

Anne-Laure Rollet (anne-laure.rollet@sorbonne-universite.fr)

\section{Abstract}

The data presented here are related to the research paper entitled "Green Earth pigments dispersions: water dynamics at the interfaces". The nuclear magnetic resonance (NMR) relaxometry data are provided for various aqueous Green Earth (GE) pigments dispersions with volume fraction spanning approximately from 0.1 to 0.5. For two of them (Cyprus GE and Bohemian GE), the NMR relaxation profiles from $10 \mathrm{kHz}$ to $30 \mathrm{MHz}\left({ }^{1} \mathrm{H}\right.$ frequency) is given for several temperatures spanning from 293 to 318K. In addition, the X-ray diffraction pattern is provided for France GE (Kremer pigments) for the identification of the main mineral component. The nitrogen gas isotherms are provided for Cyprus GE and Bohemian GE.

\section{Keywords}

celadonite, glauconite, phyllosilicate, Fast Field Cycling NMR relaxometry, water surface interaction

\section{Specifications Table}

\begin{tabular}{|l|l|}
\hline Subject & Physics - Surfaces and interfaces \\
\hline Specific subject area & $\begin{array}{l}\text { Solvent Diffusion and interaction with inorganic surfaces probed by NMR } \\
\text { relaxometry }\end{array}$ \\
\hline
\end{tabular}




\begin{tabular}{|c|c|}
\hline Type of data & $\begin{array}{l}\text { Table } \\
\text { Graph } \\
\text { Image }\end{array}$ \\
\hline How data were acquired & $\begin{array}{l}\text { Nuclear Magnetic Resonance (NMR), X-ray diffraction (XRD), Gas } \\
\text { isotherm } \\
\text { NMR relaxometer Stelar FFC spinmaster, NMR relaxometer minispec } \\
\text { Bruker } 20 \mathrm{MHz} \text {, X-ray Diffractometer Bruker D8, Micromeritics ASAP } 2020 \\
\text { instrument } \\
\text { Software: AcqNMR (Stelar relaxometer) and Minispec }\end{array}$ \\
\hline Data format & $\begin{array}{l}\text { NMR profile: .sdf (text); R1 at } 20 \mathrm{MHz} \text { : excel file .xlsx ; gas absorption: } \\
\text { excel file .xlsx ; X-ray diffractogram: bruker file .uxd } \\
\text { Raw and Analyzed }\end{array}$ \\
\hline $\begin{array}{l}\text { Parameters for data } \\
\text { collection }\end{array}$ & $\begin{array}{l}\text { Data were collected in laboratory-controlled conditions (temperature, } \\
\text { water content, pressure). }\end{array}$ \\
\hline $\begin{array}{l}\text { Description of data } \\
\text { collection }\end{array}$ & \\
\hline Data source location & $\begin{array}{l}\text { Institution: Sorbonne Université / CNRS } \\
\text { City/Town/Region: Paris } \\
\text { Country: France }\end{array}$ \\
\hline Data accessibility & $\begin{array}{l}\text { Repository name: Mendeley Data } \\
\text { Data identification number: Mendeley Data, V1, doi: } \\
\text { 10.17632/r9kht3pbn9.1 } \\
\text { Direct URL to data: http://dx.doi.org/10.17632/r9kht3pbn9.1 }\end{array}$ \\
\hline
\end{tabular}




\begin{tabular}{|l|l|}
\hline Related research article & Green Earth pigments dispersions: water dynamics at the interfaces \\
A. Fanost, M. Jaber, L. de Viguerie, J.-P. Korb, P. E. Levitz, L. J. Michot, G. \\
Mériguet, A.-L. Rollet, Journal of Colloid and Interface Science. \\
In Press.
\end{tabular}

\section{Value of the Data}

- NMR relaxometry data provide a comprehensive insight into the multiscale dynamics of water in concentrated natural phyllosilicate dispersions

- Data could benefit researches on clay science and on natural pigments used in the field of cultural heritage.

- The data allow to understand the interaction of water with the different kinds of phyllosilicate surfaces (basal and edge)

- The data allow to characterize the quality of natural phyllosilicate dispersions

\section{Data Description}

The article presents physico-chemical data about aqueous concentrated dispersions of various natural green earth (GE) pigments. The pigments are mainly composed of phyllosilicate mixtures (celadonite, glauconite, montmorillonite). The used pigments are listed in Table 1 together with their mineral's composition (according to Fanost et al. [1]). As France GE was not studied in Fanost et al. paper, X-ray diffraction pattern of France GE is presented in Figure 1 to identify the main mineral component. The average chemical composition of each mineral is given in Table 2. The data presented in this paper consist of:

- ${ }^{1} \mathrm{H}$ NMR relaxometry profiles of five GE (Figure 2): Cyprus GE, Cyprus green blue earth (GBE), Russia GE, France GE and Sennelier GE.

- $1 \mathrm{H}$ relaxation rate $\mathrm{R} 1=1 / \mathrm{T} 1$ at $0.47 \mathrm{~T}$ of water in six $\mathrm{GE}$ dispersions as a function of pigment volume fraction (Figure 3): Bohemian GE, Cyprus GE, Cyprus GBE, Russia GE, France GE and Sennelier GE.

- $\quad$ N2 gas isotherm of Bohemian GE and Cyprus GE (figure 4).

- $\quad$ The evolution in temperature of the ${ }^{1} \mathrm{H}$ NMR relaxation profiles for Bohemian GE and Cyprus GE dispersions.

Table 1: list of pigments with the main mineral component and the secondary minerals components according Fanost et al [1]. The proportions are given in \% wt.

\begin{tabular}{|l|l|l|l|l|}
\hline Pigment & Main mineral & other main minerals & Supplier & Reference \\
\hline Cyprus GE & Celadonite (70\%) & $\begin{array}{l}\text { Montmorillonite (16\%), } \\
\text { Quartz (8\%) }\end{array}$ & $\begin{array}{l}\text { Kremer } \\
\text { Pigmente }\end{array}$ & K17400 \\
\hline Cyprus GBE & Celadonite/Ferroceladonite & Montmorillonite (18\%), & Kremer & K17410 \\
\hline
\end{tabular}




\begin{tabular}{|l|l|l|l|l|}
\hline $\begin{array}{l}\text { (Green Blue } \\
\text { Earth) }\end{array}$ & (66\%), & $\begin{array}{l}\text { Anhydrite (5\%), } \\
\text { Anorthite (11\%) }\end{array}$ & Pigmente & \\
\hline Russia GE & Glauconite & Quartz, Calcite & $\begin{array}{l}\text { Kremer } \\
\text { Pigmente }\end{array}$ & K11110 \\
\hline $\begin{array}{l}\text { Bohemian } \\
\text { GE }\end{array}$ & Glauconite (88\%) & $\begin{array}{l}\text { Montmorillonite (10\%), } \\
\text { Quartz (2\%) }\end{array}$ & $\begin{array}{l}\text { Kremer } \\
\text { Pigmente }\end{array}$ & K40810 \\
\hline $\begin{array}{l}\text { Sennelier } \\
\text { GE }\end{array}$ & Gypsum & $\begin{array}{l}\text { Montmorillonite, } \\
\text { Calcite, Quartz }\end{array}$ & Sennelier & 213 \\
\hline France GE & Gypsum & & $\begin{array}{l}\text { Kremer } \\
\text { Pigmente }\end{array}$ & K40830 \\
\hline
\end{tabular}

Table 2 : chemical theoretical composition of the different minerals

\begin{tabular}{|c|c|}
\hline Mineral & Chemical composition \\
\hline Celadonite & $\mathrm{K}\left(\mathrm{Fe}^{3+}, \mathrm{Al}^{3+}\right)\left(\mathrm{Mg}^{2+}, \mathrm{Fe}^{2+}\right) \square\left[\mathrm{Si}_{4} \mathrm{O}_{10}\right](\mathrm{OH})_{2}$ \\
\hline Glauconite & $\mathrm{K}_{0.85}\left(\mathrm{Fe}^{3+}, \mathrm{Al}^{3+}\right)_{1.34}\left(\mathrm{Mg}^{2+}, \mathrm{Fe}^{2+}\right)_{0.66} \square\left[\left(\mathrm{Al}_{0.24} \mathrm{Si}_{3.76}\right) \mathrm{O}_{10}\right](\mathrm{OH})_{2}$ \\
\hline Montmorillonite & $(\mathrm{Na}, \mathrm{Ca})_{0,3}(\mathrm{Al}, \mathrm{Mg})_{2} \mathrm{Si}_{4} \mathrm{O}_{10}(\mathrm{OH})_{2} \cdot \mathrm{n} \mathrm{H}_{2} \mathrm{O}$ \\
\hline Gypsum & $\mathrm{CaSO}_{4}, 2 \mathrm{H}_{2} \mathrm{O}$ \\
\hline Calcite & $\mathrm{CaCO}_{3}$ \\
\hline Quartz & $\mathrm{SiO}_{4}$ \\
\hline Anorthite & $\mathrm{Ca}\left(\mathrm{Al}_{2} \mathrm{Si}_{2} \mathrm{O}_{8}\right)$ \\
\hline
\end{tabular}

\section{Identification of the main mineral component of France GE}

To identify the main component of France GE, X-ray diffraction pattern of France GE powder has been recorded (figure 1). The calculated diffraction pattern of gypsum $\left(\mathrm{CaSO}_{4}, 2 \mathrm{H}_{2} \mathrm{O}\right)$ from the $\mathrm{CIF}$ file [2] is also shown. 


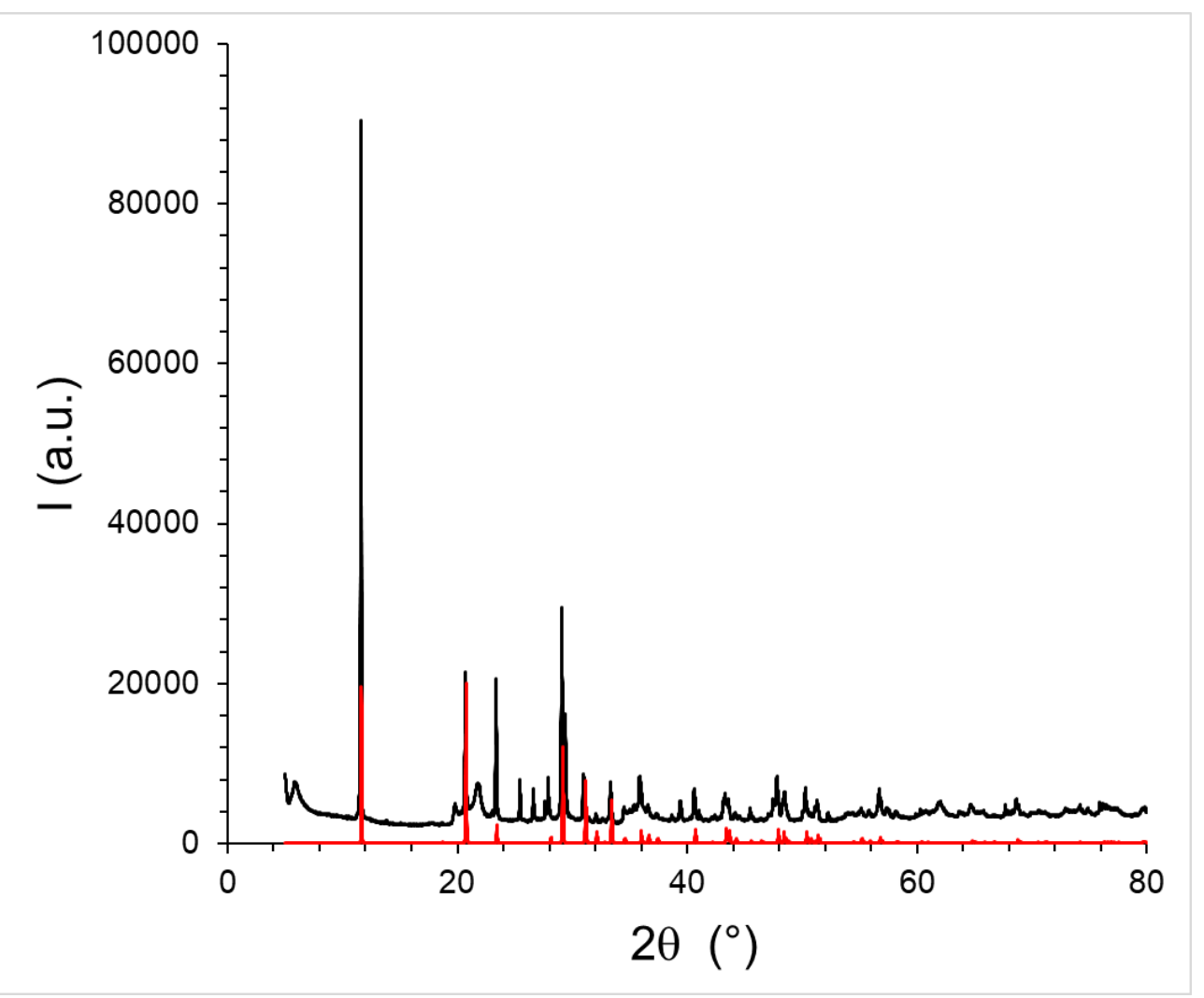

Figure 10 : XRD pattern of France GE powder (black) and calculated XRD pattern of $\mathrm{CaSO}_{4}, 2 \mathrm{H}_{2} \mathrm{O}$ from the CIF file [2].

\section{Effect of pigment volume fraction}

The ${ }^{1} \mathrm{H}$ NMR relaxation profiles of water in green earth/water mixtures with different volume fractions are displayed here for several pigments (Figure 10). The ${ }^{1} \mathrm{H}$ relaxation rates measured at frequency spanning from $10 \mathrm{kHz}$ up to $30 \mathrm{MHz}$ were determined by fitting the magnetization evolution versus time using a monoexponential function.
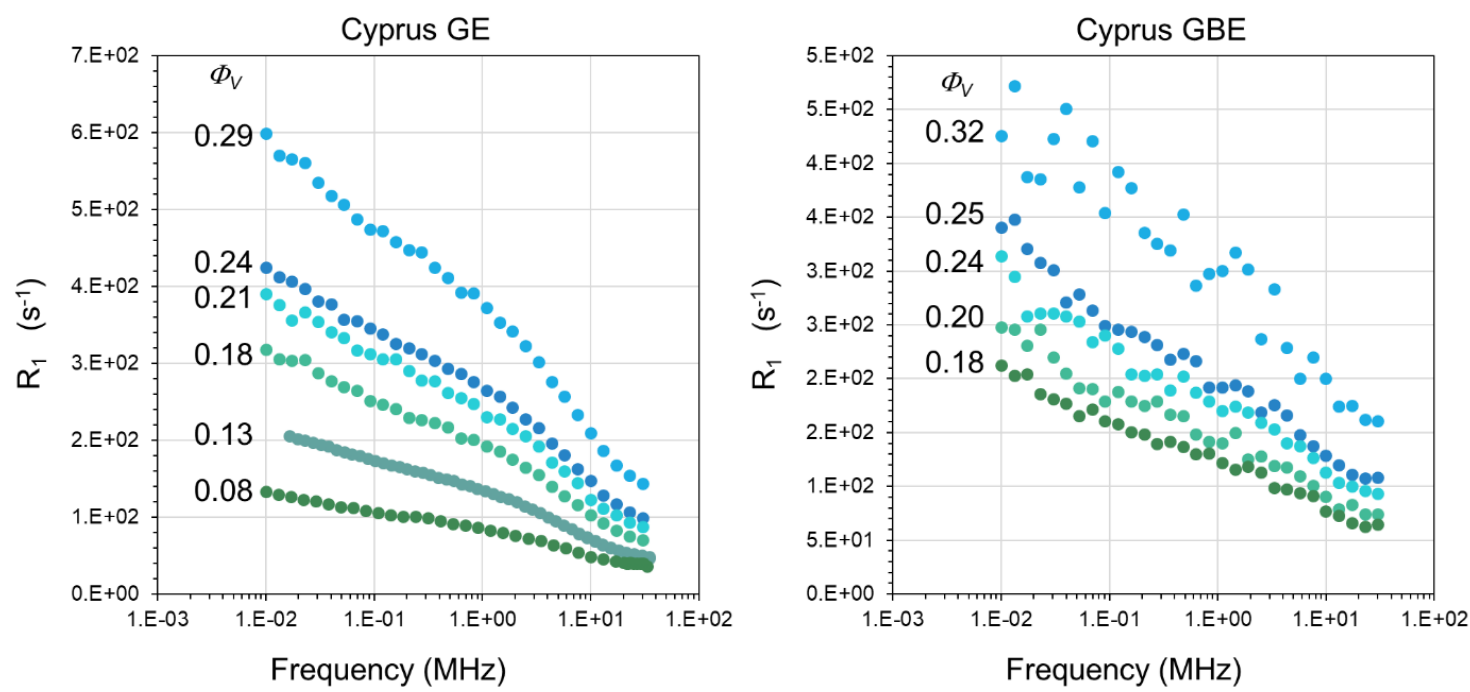

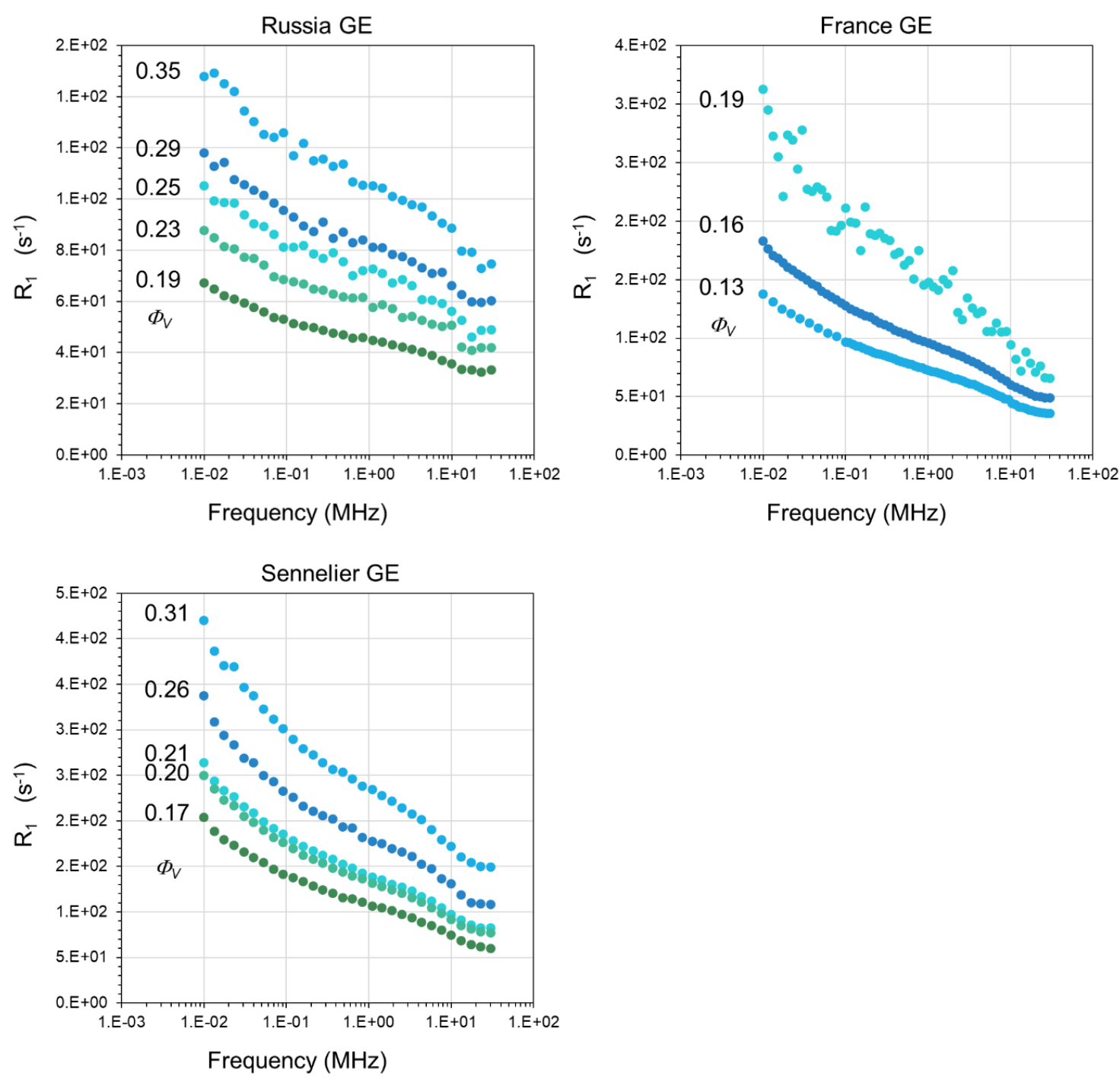

Figure $11:{ }^{1} \mathrm{H}$ relaxation rate profile of water in several GE dispersions.

The variation of the relaxation rate $R_{1}$ versus the volume fraction of pigment $\Phi_{V}$ at $298 \mathrm{~K}$ has been measured at $20 \mathrm{MHz}$ using the minispec Bruker relaxometer for several pigments. 

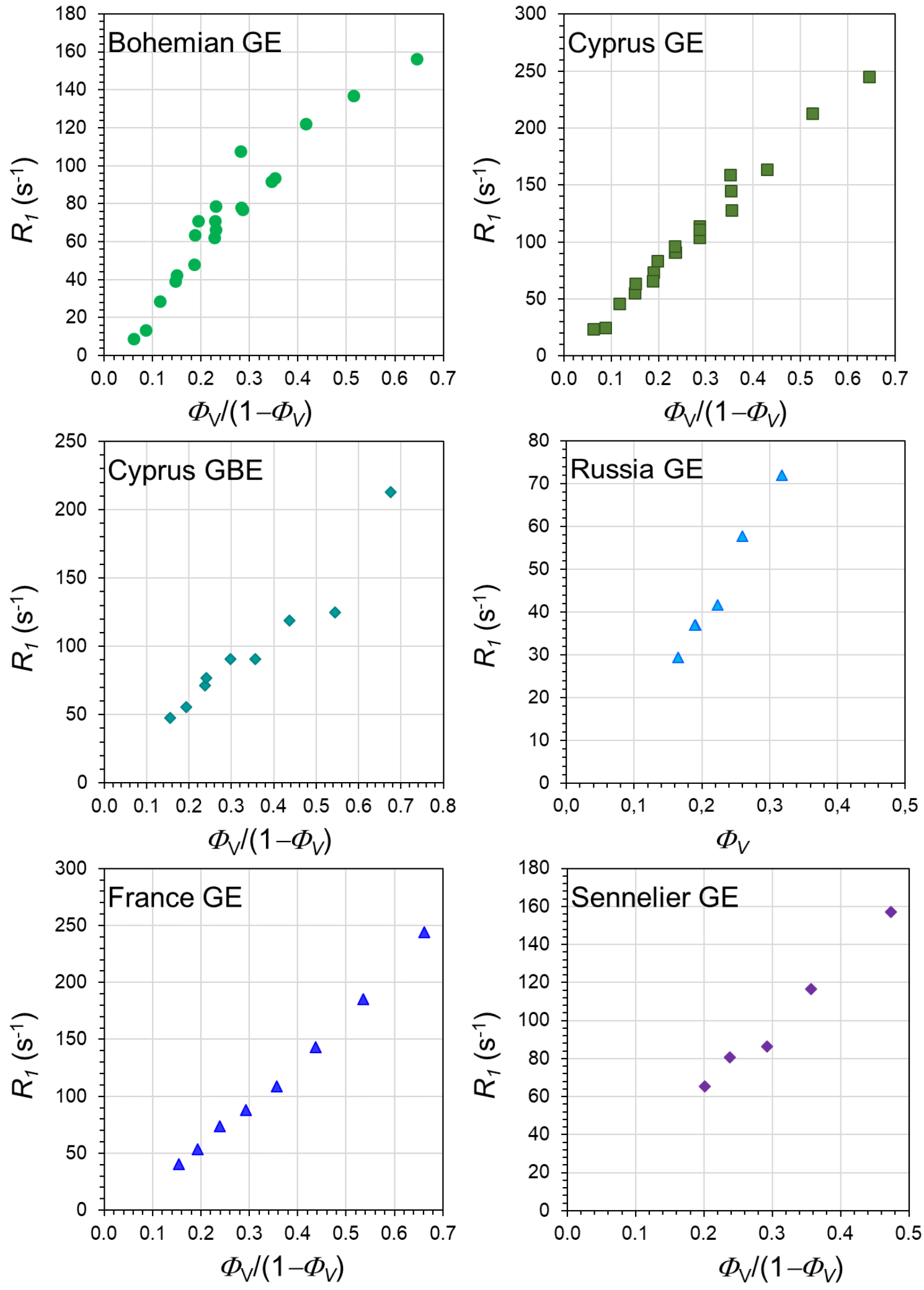

Figure 12 : Variation of $R_{1}$ as a function of $\Phi_{V}$ at $20 \mathrm{MHz}$ for different GE dispersions.

\section{Gas adsorption}

The specific surface areas were determined using the BET equation whereas the presence of micropores was assessed using the t-plot treatment [3]. Figure 13 presents the t-plot curves obtained for Bohemian GE and Cyprus GE. It appears that the sample from Bohemian GE displays significantly more micropores then the 
one from Cyprus GE. This strongly suggests that there are more defects on the edges for the Bohemian GE sample. The values deduced are $S_{\text {tot }}=66 \mathrm{~m}^{2} / \mathrm{g}$ and $S_{\text {mic }}=22 \mathrm{~m}^{2} / \mathrm{g}$ for Bohemian GE and $S_{\text {tot }}=55.7 \mathrm{~m}^{2} / \mathrm{g}$ and $S_{\text {mic }}=11 \mathrm{~m}^{2} / \mathrm{g}$ for Cyprus GE.
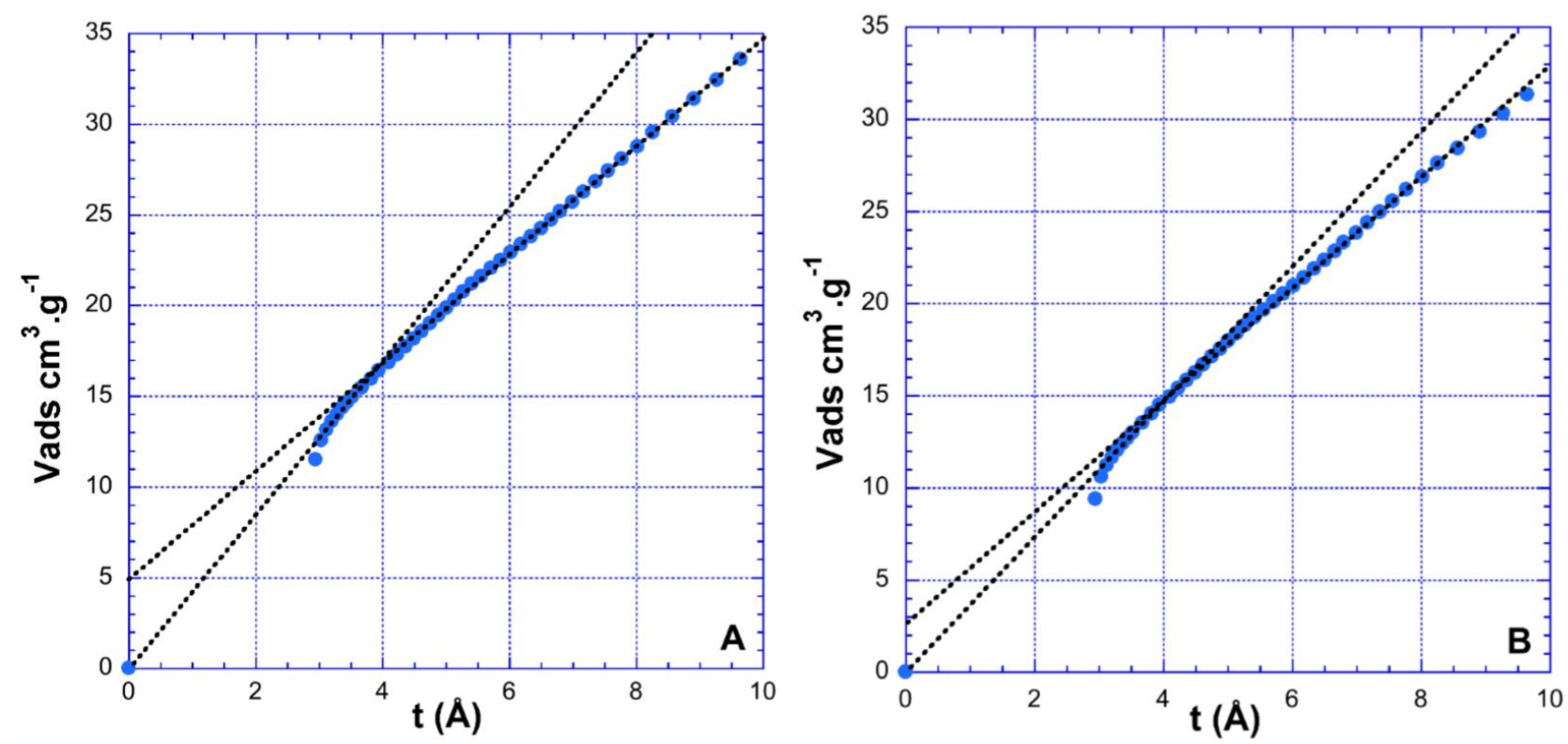

Figure 13 : t-plot curves obtained for Bohemian GE (A) and Cyprus GE (B).

\section{Temperature dependence}

The NMR relaxation profile for Boehmian GE and Cyprus GE has been measured for various temperature ranging from 293 to $318 \mathrm{~K}$ (Figure 14). For Bohemian GE the whole profile decreases with increasing temperature, while for Cyprus GE, the low frequency part is more affected.
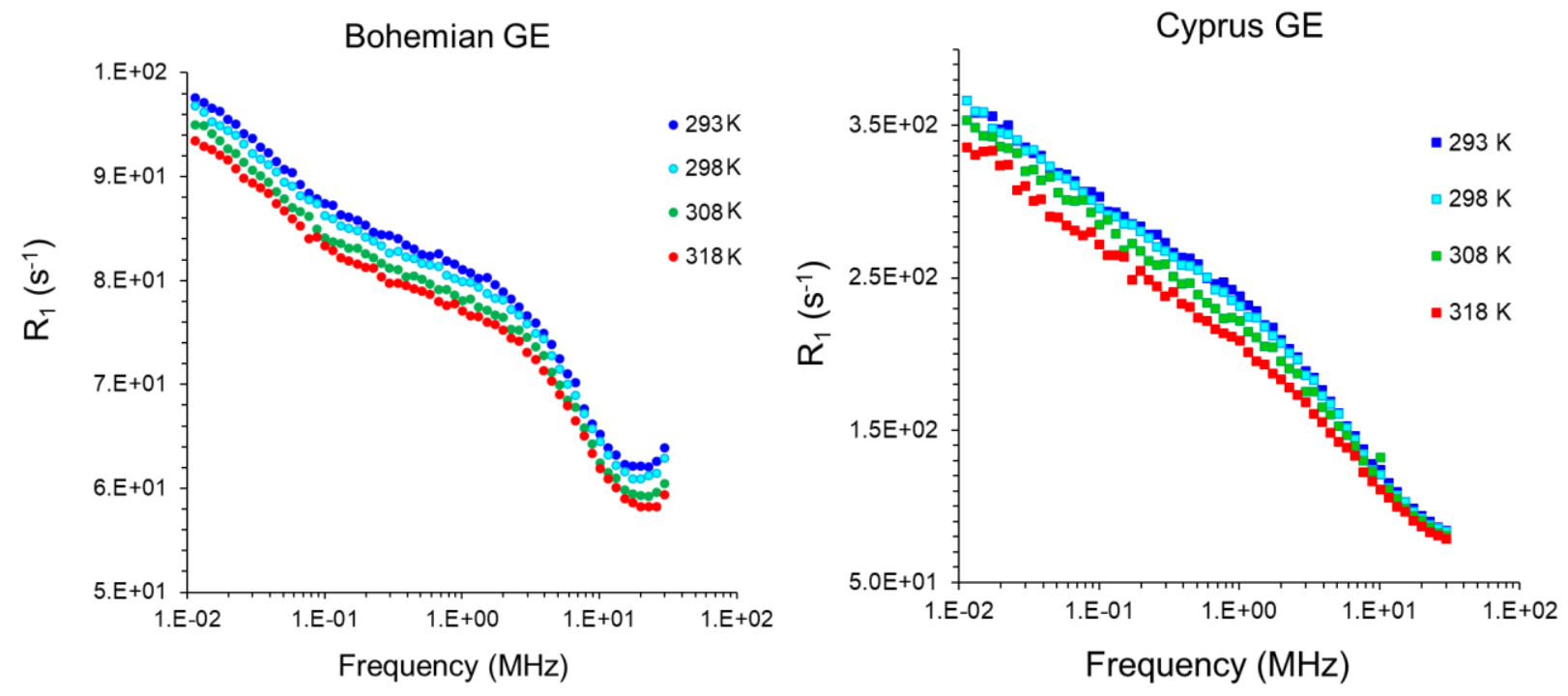

Figure 14 : NMR relaxation profile for Bohemian GE and Cyprus GE at 293k (blue), 298K (cyan), 308K (green) and $318 K$ (red).

\section{Experimental Design, Materials and Methods}




\section{Samples preparation for NMR measurements}

Several mixtures with earth/water ratio ranging between 20 to 60 weight \% were prepared by mimicking the paint tempera process, i.e. using a glass pigment muller to ensure the homogeneity of the dispersions even in concentrated pasty samples. Powdered green earth was laid on a glass plate, water was spread over it and both components were mixed using the muller until the mixture was homogenous in texture and colour. The mixing time was usually around 2 to 3 minutes. In order to prevent evaporation during the experiment, the samples were put in glass tubes $10 \mathrm{~mm}$ external in diameter and only $40 \mathrm{~mm}$ in length closed by a silicon cap and an extension was built to introduce the tube inside the relaxometer (Figure 15). Hence, the sample almost completely filled the tube and no evaporation occurs.

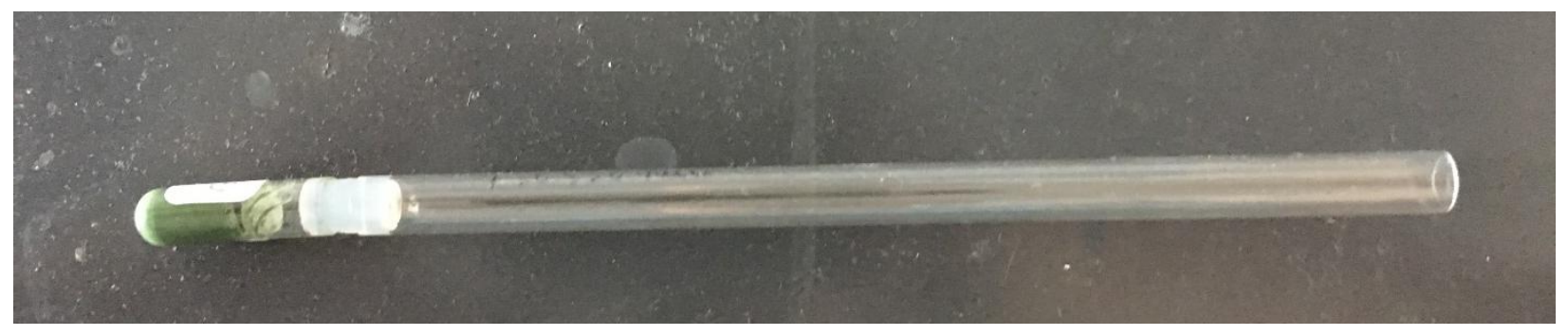

Figure 15 : picture of the sample NMR tube with its extension for introduction in the relaxometers.

\section{$X$-ray diffraction}

The X-ray diffraction pattern of France GE powder has been recorded using a Bruker D8 diffractometer equipped with a copper source emitting with a wavelength of $\lambda_{\mathrm{k}_{-} 1}=0.15406 \mathrm{~nm}$ and $\lambda_{\mathrm{k}_{\_} 2}=0.15443 \mathrm{~nm}$. X-ray diffraction patterns were measured using the following parameters: tension of acceleration, $40 \mathrm{kV}$; current, $40 \mathrm{~mA} ; 2 \Theta$ values ranging from $5^{\circ}$ to $80^{\circ}$; step, $0.010^{\circ}$ and step time, $0.75 \mathrm{~s}$.

\section{NMR relaxometry}

The measurements of the water ${ }^{1} \mathrm{H}$ longitudinal relaxation rates $R_{1}=\frac{1}{T_{1}}$ have been performed on two different NMR relaxometers. The low frequency domain from $10 \mathrm{kHz}$ to $30 \mathrm{MHz}\left({ }^{1} \mathrm{H}\right.$ frequency) has been explored using a Stelar SpinMaster relaxometer. In this case, $T_{1}$ has been measured using a pre-polarized sequence from $10 \mathrm{kHz}$ to $10 \mathrm{MHz}$ and a non-polarized sequence from $10 \mathrm{MHz}$ to $30 \mathrm{MHz}$ [4]. The recycle delay was set to $0.5 \mathrm{~s}$, the polarization was done at $20 \mathrm{MHz}$, the acquisition at $16.35 \mathrm{MHz}$, the $90^{\circ}$ pulse duration was optimized at $9.5 \mu \mathrm{s}$. For the $T_{1}$ determination, 32 logarithmically spaced recovery delays between approximately $0.01 T_{1}$ and $4 T_{1}$ were used. At $20 \mathrm{MHz}, T_{1}$ have been measured using a 20 Bruker Minispec using an inversion-recovery sequence with 32 recovery delays ranging from $40 \mu \mathrm{s}$ to $10 T_{1}$ approximately. The $90^{\circ}$ pulse duration was optimized at $9.7 \mu \mathrm{s}$. The samples were thermostated at $298 \mathrm{~K}$ (except explicitly mentioned in the text) using regulated air flux.

\section{Gas isotherm}

Sample gas isotherm are realised with a Micromeritics ASAP 2020 instrument, with $200 \mathrm{mg}$ of sample. Nitrogen adsorption isotherms were carried out at $77 \mathrm{~K}$ after outgassing the samples at $323 \mathrm{~K}$ for $24 \mathrm{~h}$.

\section{Acknowledgments}

This article is based upon work from COST Action CA15209 EURELAX "European Network on NMR Relaxometry", supported by COST (European Cooperation in Science and Technology). They acknowledge 
the Institute of Materials of Paris (IMPC) for the access of the NMR relaxometers (RELAXOME facility). Mohamed Selmane is gratefully acknowledged for conducting XRD. The NMR relaxometers and the X-ray diffractometer were funded by Sorbonne Université, CNRS and Région lle de France, and is part of The Institute of Materials of Paris (IMPC). The authours are grateful to Eva Balaven, Santiago Braley, Lorie Chahmirian, Augustin Lavirotte, Laura Maiche, Pablo Mas and Pauline Sourd, for their technical help. This work was supported by the Observatoire des Patrimoines of Sorbonne Université (OPUS).

\section{Declaration of Competing Interest}

The authors declare that they have no known competing financial interests or personal relationships which have, or could be perceived to have, influenced the work reported in this article.

\section{References}

[1] A. Fanost, A. Gimat, L. de Viguerie, P. Martinetto, A.-C. Giot, M. Clémancey, G. Blondin, F. Gaslain, H. Glanville, P. Walter, G. Mériguet, A.-L. Rollet, M. Jaber, Revisiting the identification of commercial and historical green earth pigments, Colloids and Surfaces A: Physicochemical and Engineering Aspects. 584 (2020) 124035. https://doi.org/10.1016/i.colsurfa.2019.124035.

[2] P. Comodi, S. Nazzareni, P. F. Zanazzi, S. Speziale, High-pressure behavior of gypsum: A single-crystal Xray study, American Mineralogist, 2008, 93, 1530-1537. https://doi.org/10.2138/am.2008.2917.

[3] L. J. Michot, Determination of surface areas and textural properties of clay minerals, in: Developments in Clay Science, Elsevier, 2018: pp. 23-47.

[4] E. Anoardo, G. Galli, G. Ferrante, Fast-field-cycling NMR: Applications and instrumentation, Applied Magnetic Resonance. 20 (2001) 365-404. https://doi.org/10.1007/BF03162287. 